\title{
Hazard analysis and critical control point (HACCP) in seafood processing: an analysis of its application and use in regulation in the Sultanate of Oman
}

Article

Accepted Version

Creative Commons: Attribution-Noncommercial-No Derivative Works 4.0

Al-Busaidi, M. A., Jukes, D. J. and Bose, S. (2017) Hazard analysis and critical control point (HACCP) in seafood processing: an analysis of its application and use in regulation in the Sultanate of Oman. Food Control, 73. pp. 900-915. ISSN 0956-7135 doi: https://doi.org/10.1016/j.foodcont.2016.09.042 Available at https://centaur.reading.ac.uk/67639/

It is advisable to refer to the publisher's version if you intend to cite from the work. See Guidance on citing.

To link to this article DOI: http://dx.doi.org/10.1016/j.foodcont.2016.09.042

Publisher: Elsevier

All outputs in CentAUR are protected by Intellectual Property Rights law, including copyright law. Copyright and IPR is retained by the creators or other copyright holders. Terms and conditions for use of this material are defined in the End User Agreement. 


\section{CentAUR}

Central Archive at the University of Reading

Reading's research outputs online 
Control

Elsevier Editorial System(tm) for Food

Manuscript Draft

Manuscript Number: FOODCONT-D-16-01517R2

Title: Hazard Analysis and Critical Control Point (HACCP) in Seafood Processing: An Analysis of its Application and Use in Regulation in the Sultanate of Oman

Article Type: Research Paper

Keywords: Seafood; HACCP; Pre-requisite programmes; Trade; Food Safety and Quality; Oman

Corresponding Author: Mrs. Moza A. Al-Busaidi, Msc

Corresponding Author's Institution: The University of Reading

First Author: Moza A. Al-Busaidi, Msc

Order of Authors: Moza A. Al-Busaidi, Msc; David J Jukes, Associate Professor of Food Regulation; Shekar Bose, Associate Professor

Abstract: When considering the supply of fish products to consumers, the adoption of food safety management systems throughout the 'net to plate' continuum is of a paramount importance. It is essential to safeguard consumers and to facilitate regional and international trade.

This study has assessed the technical barriers and benefits associated with the implementation of management system incorporating HACCP and related pre-requisite programmes in the seafood processors in the Sultanate of Oman.

A survey, using qualitative surveys and interviews, was conducted out to verify the level of implementation of the seafood safety and quality requirements. A total of 22 (92\% returned) HACCP processors, and 15 (83\% returned) non-HACCP processors and 15 (75\%) officials completed the questionnaires.

Differences between processors operating with or without a HACCP system in place have been identified. The survey of local officials provided an additional perspective on the issues involved. The implications of handling practices in the seafood supply chain, seafood trade and the cost implications of implementing HACCP-based food safety management systems were also assessed.

In comparison to the non-HACCP processors, the results indicated that HACCP firms were more diversified in their export markets and were able to target the more lucrative markets such as EU, Japan and America. However, the processors felt that the main barrier for exporting to these markets was the restriction imposed by the government on exporting certain species which reduced their ability to meet contracts with these countries. The study has also shown inadequate execution of prerequisite programmes due mainly to lack of training delivered to food handlers and a poor knowledge of food safety concepts. In particular there is an overreliance on the use of CCPs to control hazards when prerequisite programmes would be more appropriate is many situations.

When considering whether to implement HACCP-based control systems, the seafood processors identified barriers linked to costs as their main concerns. However, whilst recognising this issue, the officials also 
highlighted barriers linked to the lack of expertise, skills and commitment of the staff.

In general, the study highlighted significant gaps which undermine the effectiveness and success of implementing safety and quality requirements to meet national legislative obligations. These include: poor attitudes and understanding toward HACCP and its pre-requisite programmes, lenient enforcement by the authorities, the lack of training and consultancy organizations in the country, a lack of awareness. The overlapping structure of the regulatory authorities in the country and the distribution of national inspection resources have also been identified as an issue of concern. 


\section{Dear Editor,}

I am enclosing herewith a manuscript entitled " Hazard Analysis and Critical Control Point (HACCP) in Seafood Processing: An Analysis of its Application and Use in Regulation in the Sultanate of Oman" in your esteemed journal "Food Control" for possible evaluation and publication.

With the submission of this manuscript I would like to confirm that the above mentioned manuscript has not been published elsewhere, accepted for publication elsewhere or under editorial review for publication elsewhere.

\section{Kindest Regards,}

Moza A. Al-Busaidi (Corresponding Author)

University of Reading

E-mail: M.A.A.Al-Busaidi@pgr.reading.ac.uk

(on behalf of all authors) 


\section{Reviewers' comments:}

Reviewer \#2: The work is now of easier reading, but it lacks of some other information.

Lines 6-8: please indicate the scientific name of the cited species

Difficult to mention all the scientific names for each of the mentioned species, as they are many types of tuna, kingfish and etc. And the used reference in this manuscript mentioned only the generic names.

Lines 7-8: is "abalone" a crustacean or a univalve mollusc?

The word crustacean has been deleted to reduce confusion.

Lines 160: please indicate the scientific name of the cited species

Scientific names have been added.

Please evaluate if eliminate some paragraphs or subsections in the section "Results and discussion"; the work is now of easier reading but in my opinion it is still too long (7213 words include figures and tables, as specified in "Guidelines for authors"?)

We believe to reduce it further would be detrimental to the value of the paper.

Reviewer \#4: The subject is interesting and has a central importance in the development of HACCP methodology in Sultanate of Oman.

After corrections made to the manuscript, it meets conditions to be published.

Nevertheless, the manuscript, in my opinion, is improvable in some aspects, according to the

following suggestions:

1) Line 74, the authors must indicate a reference that explains the "Likert scales".

The reference has been added as requested.

2) line 163, authors should remove the space at the beginning of the sentence.

3) line 188, authors should remove the space at the beginning of the sentence.

4) line 256, authors should remove the space at the beginning of the sentence.

5) line 259 , authors should remove the space at the beginning of the sentence.

6) line 397, authors should remove the space at the beginning of the sentence.

Comments 2-6: there are no spaces at the beginning of the mentioned sentences in the original manuscript, and maybe these spaces appeared once the original manuscript has been transformed into PDF document.

7) Table 1, needs a review since in the line "Length of service in seafood industry (years)" it's not clear the presence of a symbol with a "?".

This symbol may have been introduced during generating a PDF document as in not present in the original manuscript.

8) Table 2 needs a review since the used asterisks "*" are not explained; "n\%" lines need a space 
between the number and the percentage, like "13 (59\%)"; and the zero value displays incorrectly decimal places. In this last point, authors should use zero value without decimal places and introduce the zero percentage value, like "0 (0.0\%)".

Corrected

9) Table 3 needs a review, authors should in line "Non- HACCP processors" remove the space before "HACCP" and add a parenthesis after (TBT).

Corrected

10) in Table 4, authors should remove the empty line before "sampling plan" line Empty line may have been introduced during generating a PDF document as in not present in the original manuscript.

11) in Table 5, authors should add a decimal place in the percentage value in all results: "3 (20\%)" and "6 (40\%).

Corrected

12) in Table 6A, authors should add "0 (0.0\%) in line "GHPs" and column "Dis-Agree frequency (\%)".

Corrected

13) in Table 6B, authors should add a decimal place in the percentage value in all results: "3 (20\%)".

Corrected

14) in the list of tables and figures, authors should change in Figures 7 to 10 the one "1" to first "1st" and five " 5 " to fifth " 5 th".

Corrected 
Hazard Analysis and Critical Control Point (HACCP) in Seafood Processing: An Analysis of its Application and Use in Regulation in the Sultanate of Oman

\author{
Moza A. Al-Busaidi (Corresponding Author) \\ University of Reading \\ Department of Food and Nutritional Sciences, Whiteknights, Reading RG6 6AP, UK \\ E-mail: M.A.A.Al-Busaidi@reading.ac.uk \& moza_albusaidi@yahoo.com \\ David J. Jukes \\ Associate Professor of Food Regulation \\ University of Reading \\ Department of Food and Nutritional Sciences, Whiteknights, Reading RG6 6AP, UK \\ "David Jukes" <d.j.jukes@reading.ac.uk> \\ Shekar Bose \\ Associate Professor \\ Sultan Qaboos University \\ Department of Natural Resource Economics, College of Agricultural and Marine Sciences. \\ P.O.Box 34, Al-Khod, Postal Code 123 Muscat, Sultanate of Oman
}




\section{INTRODUCTION}

In the Sultanate of Oman, seafood production is of paramount importance in providing employment, food security, and foreign currency. The total production in 2014 amounted to 211 thousand tonnes with $63 \%$ being exported to nearly 50 countries with an export value of 83 million O.R. (US\$215.6 million). The country is considered to be self-sufficient in terms of seafood production and much of its production is consumed locally. The most commercialized seafood species in Oman include tuna, kingfish, large jacks, sardine, emperors, grouper, seabream, cuttlefish, lobster, shrimp and abalone (FSB, 2015). However, with large quantities being exported local shortages have occurred and the government, led by the Ministry of Agriculture and Fisheries, has imposed restrictions. A decision in 2010 led to the banning of exports of certain fish species whilst others are now subject to specific quotas for internal and export markets.

Adopting food safety management systems throughout the 'net to plate' continuum is of paramount importance in safeguarding consumer's well-being and facilitating regional and international trade. The Omani government has made progress in implementing HACCP systems and improving food safety controls. The Fishery Quality Control Centre (FQCC), as part of the Ministry of Agriculture and Fisheries (MAF), is the premier agency in Oman with the legal power to enforce and implement the seafood safety and quality requirements stipulated in the national Fishery Quality Control Regulation and its related guidelines and standards (Al-Busaidi \& Jukes, 2015; Al-Busaidi, Jukes, \& Bose, 2016). We have previously analyzed the structure of the seafood supply chain (Al-Busaidi et al., 2016) and noted that it is based on traditional practices and characterized by being a complex system linking different stakeholders from fishermen to consumers. Distribution of seafood products can involve a lengthy chain which, due to seafood perishability, accelerates the decline of its quality and safety. Overall, the food safety control system in Oman has a multiagency structure with the current food safety law and regulations shared across various governmental authorities with overlapping responsibility and mandates (Al-Busaidi \& Jukes, 2015).

In light of these factors, taking the Sultanate of Oman as the basis for the study, we have evaluated the issues relating to HACCP implementation in the seafood industry and the role of the regulatory authorities. In particular, the study collected data on the perceived benefits and barriers of implementing HACCP. Since currently the use of HACCP is not a legal requirement, our analysis is based on two groups of processors: those who have implemented HACCP (the 'HACCP processors') and those who do not operate a HACCP based safety system (the 'non-HACCP processors'). Local officials were also surveyed to provide an additional perspective on the issues involved. The implications of handling practices in the seafood supply chain on the safety and quality of seafood, seafood trade and the cost implications in implementing HACCP based food safety management systems were also assessed.

\section{MATERIALS AND METHODS}

\subsection{Business}

An interview-based qualitative survey was conducted with seafood processors and officials from the regulatory authorities in charge of implementing seafood safety and quality requirements in the Sultanate of Oman in the period from August 2015 to February 2016. Study criteria were established to include only the seafood processors with some elements of food safety and quality systems in place, with processing operations (and not just storage), and with potential to export to regional and international markets. In addition processors meeting the criteria were selected to ensure representation from small, medium and large businesses. Excluded were those who did not fulfil these criteria or were under construction and/or not operational during the study. 
The processors were segregated into distinct groups based on their hygiene status: the HACCP processors (seafood processors implementing the HACCP requirements) and non-HACCP processors (seafood processors not implementing the HACCP requirements and have basic hygiene standards in place). To gain further insights into the divergences between these two groups, the data was analysed to provide cross-validation between the responses of the processors and the officials. A list of 50 processing establishments was provided by the Ministry of Agriculture and Fisheries. The processors that fulfilled the study criteria were contacted and 42 were selected for the survey. 8 processors under construction were excluded. The selected processors were visited and handed questionnaires of which a total of $37(88 \%)$ were completed and returned. A total of $22(92 \%$ returned) HACCP processors, and 15 (83\% returned) non-HACCP processors completed the questionnaires. For the officials, 20 were contacted and 15 (75\%) completed questionnaires were obtained. The contacted officials were from the Ministry of Agriculture and Fisheries and were selected based on their official role and experience in the field of seafood safety control. Their roles varied between seafood safety inspectors, section heads and directors of the different departments that deal with seafood safety control.

The processors and officials were located in varied governorates across Oman. The majority of the processes were based in the Al-Wusta governorate (30\%), followed by Muscat (24\%) and Al-Sharqiya $(24 \%)$ governorates. Most of the officials $(73 \%)$ were based in the Muscat governorate where the main headquarters for seafood control is located.

Prior to conducting the survey, ethical approval was obtained from the University of Reading and an approval was given by the appropriate authority in Oman. The data collected was treated confidentially and anonymously.

\subsection{Questionnaire design and development}

It had been decided to use an interview-based qualitative survey as the main method of data collection supplemented by qualitative responses from interviews with key personnel from the three groups. In addition, inspection reports covering the previous 12 months from the Fish Quality Control Centre (FQCC) were examined to provide a means of verifying some of the data.

The questionnaires used a mixture of closed questions, open questions and attitudinal scales based on five-point Likert scales (Likert, 1932) and designed to provide a valid and accurate measure of an individual's responses. Although 3 separate questionnaires were prepared for the 3 groups, the majority of the questions were common so as to allow comparison and to provide cross-validation of the responses. After drafting, all 3 questionnaires were translated so as to provide both English and Arabic language versions.

Each questionnaire was divided into seven sections. Sections 1 and 2 sought general information of the responder and the processor. Section 3 was on the seafood trade and business issues and Section 4 looked on the seafood supply chain. Section 5 mainly dealt with prerequisite programmes - an essential component for HACCP implementation. For the HACCP-processors, Sections 6 assessed the level of implementation of HACCP principles and requested some financial information on the costs associated with HACCP implementation. In the final Section, all groups were encouraged to rate the effectiveness of the Omani food and seafood safety legislation and the work of the control authorities.

After checking with an independent expert, an academic specialized in the HACCP system, the questionnaires were piloted on four processors (2 for each of the HACCP and the non-HACCP processors) and three officials from the FQCC and, based on these responses, modifications were made. 


\subsection{Statistical analysis}

A Statistical Package for Social Science (SPSS) version 21 was used to process and analyse the data. Descriptive analysis and frequencies were computed for the variables of the study. Cross tabulations and Fisher's exact Chi-square $\left(\mathrm{X}^{2}\right)$ test was used to examine the relationships between and among the different variables.

\section{RESULTS AND DISCUSSION:}

\subsection{Characteristic and demographic details of the Seafood Industries in Oman}

General characteristics of the respondents participating in the study are presented in Table 1. For the HACCP processors, the majority (64\%) of the respondents were quality controllers, for the nonHACCP processors they were the owners (80\%); for the officials the largest group was inspectors (47\%). These proportions correspond well with Qatan et al. (2015). Professional experience in the seafood industry varied among the respondents of the three groups with $47 \%$ having above 20 years for the non-HACCP group, 59\% having less than 10 years for the HACCP group, and $60 \%$ within the range of 11-19 years for the officials. The HACCP processors and the authority were more willing to employ staff with degree-level training; the owners of the non-HACCP processors were less likely to employ qualified personnel as they depend more on their own experience and that of experienced staff. This interpretation agrees with that of Jin, Zhou, and Ye (2008) which indicated that managers of HACCP processors are more educated and willing to implement HACCP principles in their businesses. The higher the education levels of the managers of the processors the less the requirement of support and consultancy from the government (Karaman et al, 2012).

Only $14 \%$ of the respondents within the HACCP processors were Omani; for the non-HACCP group it was $53 \%$ and these were mostly the owners. All officials were Omani. Qatan et al. (2015) had a similar profile and suggested several possible causes: shortage of local expertise in seafood safety and quality, reluctance of Omanis to work in this field and/or cost minimization by the processors.

Information on the processors' business profiles is presented in Table 2. The survey included small, medium and large establishments. Most process mainly fresh and frozen seafood products with only one HACCP processor producing canned products and only one non-HACCP processor undertaking drying and salting. Those in the HACCP group were likely to employ more workers and these were mostly non-Omani. Although both groups of processors target the domestic and foreign markets, most products from the non-HACCP group go to the domestic markets (93\%) in comparison to $73 \%$ for the HACCP group. The lucrative markets such as the European Union (EU), the USA and Japan are mostly targeted by processors from the HACCP group since they fulfil these markets' requirements. However, the share of the end products going to these markets has decreased due to the ban in 2010 on exports of certain species that was imposed by the MAF in order to limit the export of high valued seafood products and increase their availability for local consumers. Other markets have been targeted by both groups with more diverse products but mostly focused on marketing low value species to the Asian and African markets. Most of the raw seafood materials are obtained locally: $77 \%$ for the HACCP group and $100 \%$ for the non-HACCP group. The HACCP processors often use imported raw materials due to the seasonality of certain species in Omani coastal waters.

The majority of the respondents from both categories declared their capacity to be below 5000 metric tonnes (MT) per year, with only $15 \%$ and $6.7 \%$ exceeding 10,000 MT per year for HACCP and non-HACCP processors respectively. Processors in the HACCP group tended to have a larger turnover with only $2(12 \%)$ processors indicating an annual turnover of less than 1 million dollars compared to 
7 (54\%) in the non-HACCP group. However, there were some large non-HACCP processors (4; 31\%) that had an annual turnover above 10 million dollars. This was partly caused by some of these processors being suppliers of raw seafood to the HACCP processors.

\subsection{Seafood trade and business issues}

The markets are shown in Figure 1, where the HACCP processors were more diversified and targeted the more lucrative markets such as EU, Japan and America.

The questionnaire asked about the level of difficulty of accessing different markets in terms of satisfying their quality and safety requirements - mean value of the responses are shown in in Figure 2 based on a five-point scale ranging from "very difficult" (5) to "very easy" (1). The non-HACCP processors perceived the lucrative export markets as very challenging and difficult to break into. The HACCP processors were less concerned about the difficulty since they satisfy the key HACCP requirement and were experienced in dealing with these markets. The officials were more discriminating and viewed the EU, Japanese and the American markets as the most difficult to access, with the Asian, African and Arabian/GCC countries as the easiest.

Results (Table 3) indicate that the main barrier for exports to regional and international markets was the restriction imposed by the MAF on export of certain species. With the imposition of these controls most exporters lost their valuable contracts as they were unable to ensure continuity of supply and switched to low valued seafood targeting less lucrative markets. Some have given up their HACCP certification as compliance is largely market driven - a similar attitude has been reported in a study of the Australian food industry (Ropkins \& Beck, 2000).

Data on the barriers to enhanced operations is shown in Figure 3. The scale shows the mean values of the barriers that are likely to prevent the enhancement of the seafood business operation rated by the officials, HACCP and Non-HACCP processors based on a five-point Likert scale ranging from "major barrier" (5) to "not a barrier" (1). Once again the MAF export ban, although relating to only certain fish species harvested locally (for example Kingfish (Scomberomorus commerson), Longtail tuna (Thunnus tonggol), Yellowfin tuna (Thunnus albacares) and certain species of Grouper such as Epinephelus diacanthus) was also seen as the major barrier preventing the enhancement of operations. Sudden changes in government policies without giving the business a time frame to adjust their practices was seen as the second barrier - probably also linked to the export ban. Although not ranked in the top group, staff turnover was also considered a barrier for many firms but it was more significant to the non-HACCP processors in comparison to the HACCP processors. The non-HACCP processors mostly employ workers with low level of education and expatriate, seasonal or non-permanent workers since they are much cheaper to employ and there is a reluctance to provide adequate training as its considered time consuming and a financial burden. Mol et al (2014) reported a similar situation in the Turkish seafood processing sector.

\subsection{Food Safety Management Systems (HACCP and its pre-requisite programs)}

Seafood products are often exposed to lengthy handling and distribution processes before reaching the consumers and, given its perishability, its safety can be adversely affected if controls are inadequate (Al-Busaidi et al., 2016).

The quality and safety of raw material received from suppliers of local raw seafood products were rated highly by the respondents in comparison to imports. Figures 4 and 5 , show various stages and factors in the supply chain that may impose negative effects on the quality and safety of seafood products. The officials believed that the practices adopted by the fishermen, landing sites and middlemen/truckers are the stages that contribute negatively to the quality and safety of seafood products. With a mean score of 3.0, it is interesting to note that in Figure 4, the non-HACCP 
processors gave 'negative' scores (higher than 3.0) for all the suggested factors whereas both the officials and the HACCP processors were much more discriminating.

In terms of the different factors that lead to deterioration in the safety and quality of the seafood products, inadequate control of time and temperature and poor ice availability were reported as the major impact on the seafood products as shown in Figure 5.

\subsubsection{Prerequisite programmes}

The processors were asked about the level of implementation of prerequisites programmes within the different stages of their processing. The officials were also asked for their assessment of the same prerequisites so as to verify the responses of the processors. The responses are shown in Figure 6.

The HACCP processors rated their implementation of prerequisites highly; the officials were mostly in agreement with these responses - for example the maximum difference in mean scores was only 0.80 for 'personal hygiene'. The non-HACCP processors also rated their implementation quite high; however, the officials disagreed with this rating giving much lower scores to all pre-requisite elements. This is seen by the difference in scores varying between a minimum of 0.87 and a maximum of 2.00. The data shows a lack of knowledge of prerequisite programmes in the nonHACCP processors. This could be due to various factors: the lack of education, lenient enforcement by the regulators or a lack of finance. Similar suggestions have been made by Jin et al. (2008) following their research into food enterprises without HACCP in China.

Prerequisite programmes are considered the foundation of effective HACCP implementation. Even within the EU it has been reported that it is common to misunderstand the different roles of prerequisites and HACCP both by authorities and food businesses (Food and Veterinary Office, 2015). This situation can also be found in the Omani seafood industries where, due to the need to meet the EU market requirements in the 1990's, the process was rushed and prerequisite programmes were not given enough consideration. Our review of the official inspection reports confirmed that a major problem with seafood processors was the absence or failure to follow prerequisite requirements. Similar results have been reported by other researchers (Murat Bas et al., 2007; Doménech et al., 2011; Tomasevic et al., 2013).

The questionnaire asked where in the operation critical control points (CCPs) were situated. The most selected CCPs were raw material reception (33\%) followed by cooling/chilling (17.3\%), processing (17.3\%), raw material suppliers (13.5\%) and storage (13.5\%). The least selected was the cooking step as most of the processors deal with fresh and frozen product - only the canning processors, where retorting occurs, considered it as a CCP. This clearly indicates a degree of confusion in the application of HACCP as correct temperature control ('cooling/chilling') is fundamental to the processing of seafood and should really have been included by all processors as a CCP. $23 \%$ of the HACCP processors indicated they had 6 or more operational steps where CCPs have been identified. This suggests an excessive reliance on the use of CCPs when control using their prerequisite programmes would be more appropriate is many situations.

During the last three decades, the HACCP system and its prerequisite programmes have been progressively introduced into the seafood industries in Oman. The adoption of HACCP principles by the seafood processors however, has not progressed easily (Al-Busaidi et al., 2016). Prior to 2009, food safety management systems (FSMS), particularly the HACCP system, were enforced by the seafood safety authorities on the processors that were exporting to the European markets. The processors received a lot of support from these authorities to implement the system. However those not willing to adopt the system had much less support and were only inspected periodically by other food safety enforcement authorities. However, after the amendment of the Fishery Quality 
Regulation (12/2009) in 2009, all seafood processors are expected to adopt a food safety system with HACCP a preferred method. Nonetheless, pressure from seafood importing countries is the major factor currently demanding HACCP application making HACCP a market driven system rather than a locally driven safety and quality practise.

Asked about the time required from starting to implement the system, $68 \%$ of the HACCP processors stated that it took them less than 6 months with $50 \%$ of the processers receiving guidance from officials of the FQCC. Other studies have reported varying time: in the Mexican and Chinese meat industries it was reported to be around 29 and 42 months respectively (Maldonado-Siman et al., 2014); in both the Australian meat industries (Khatri \& Collins, 2007) and in food businesses in China (Bai et al., 2007) the time varied between 6-12 months; in the Serbian meat industry $50 \%$ of the processors estimated the period to be 12 months or less with $11.7 \%$ indicating more time was required (Tomasevic et al., 2013).

$64 \%$ of the processors believed that they fully participated in the development of their HACCP plan, and they all, to varying degrees, considered that they were participating in its day-to-day operation. The majority of the officials considered that most of these processors performed the above tasks. Most of the respondents considered that they fully implement all the seven principles of HACCP; however, the officials were less positive only classing implementation at the 'most' to 'some' level of implementation.

\subsubsection{Barriers of implementing and operating HACCP system}

The processors were shown a list of 14 'barriers to implementing HACCP' and were asked to identify the top five barriers. Of the 15 non-HACCP processors, only 9 felt that they had sufficient knowledge to answer making a total of 31 processor responses. Combining the two groups, those barriers which were selected the most were:

1. Requirements to restructure the facility ( $65 \%$ included this item)

2. HACCP requirements added cost to the final product (61\%)

3. Inadequate infrastructure and facilities (45\%)

4. Consumer/market not requiring HACCP (45\%)

5. Lack of financial resources $(42 \%)$

6. A need to retrain production staff (42\%)

The order of the list corresponds to that of the HACCP processors taken on their own. For the nonHACCP processors, the items are the same although the order was different - for example, the need to retrain staff was ranked second equal (67\%) with requirements to restructure the facilities whilst the cost of HACCP was their first concern (at 78\%). However, as the questionnaire asked for the barriers to be ranked from "the first highest barrier" to the fifth highest barrier", a more detailed analysis is possible and data from this is shown in Figure 7.

The officials were asked a very similar question on the top five barriers, but they considered the issue generally from their experience rather than linked to a specific business. Their top six show a rather different selection:

1. Requirements to restructure the facility ( $87 \%$ of officials included this barrier)

2. Lack of expertise and/or technical support (60\%)

3. Lack of top management commitment/dedication (53\%)

4. Lack of knowledge on how to implement HACCP (53\%)

5. Lack of financial resources $(53 \%)$

6. Inadequate infrastructure and facilities (53\%) 
The more rigorous food safety controls required by HACCP suggest to the respondents that significant alterations to their business's structure are required although this should be a factor in their operation whether or not HACCP is employed. Although all groups put the requirement to restructure as their top barrier, it is interesting to note that the officials had greater concerns about the expertise, skills and commitment of the staff whereas the processors tended to select items more related to the costs of HACCP.

The HACCP implementers were also requested to provide the negative impacts they faced once they had decided to adopt HACCP. The ranking of negative factors was in agreement with those of Khatri \& Collins (2007) and Maldonado-Siman et al. (2014) in finding product testing as a major operating cost. Nevertheless, in regard to the cost of investing in new equipment and staff training, Khatri \& Collins (2007) reported them as one of the major costs in the meat industries in Australia.

\subsubsection{Motivation and benefits arising from adopting HACCP system in the seafood industry}

Successful implementation of any FSMS requires sufficient knowledge and commitment from administrative and production staff. The officials and both types of seafood processors agreed on the benefit of adopting FSMS system.

\section{Motivation}

The participants were presented with a list of 14 potential motivational factors and were requested to select and rank the top five factors when their businesses decided to implement HACCP. For the HACCP processors, the motivational factors selected the most were as follows:

1. Improved product quality and safety (91\% of HACCP processors included this item)

2. Meet quality and safety requirement of customers $(55 \%)$

3. Consumer protection (55\%)

4. Meet with requirements of national, regional and international laws and regulations (45\%)

5. Enhanced reputation of establishment (41\%)

It is pleasing to note that the top three items focus on the consumer benefit of adopting HACCP. The list from officials was very similar although their list had a different factor (Increased ability to retain or access new export markets) in fifth place perhaps reflecting the recognition that the officials' role is often linked to ensuring processors gain access to export markets.

The responses by all the groups varied within the ranking from "the first highest motivation" to the "fifth highest motivation" for each motivational factor which is illustrated clearly in Figure 9.

\section{Benefits}

The HACCP processors were also asked to provide the top benefits once they had implemented the HACCP system as shown in Figure 10. The improvement of the quality and safety of the seafood products was also selected as the top benefit of adopting the HACCP system. Similar results to our study in terms of the HACCP system improving the products quality and safety have been reported (Murat Bas et al., 2007; Jin et al., 2008; Karaman et al., 2012; Qatan, 2010; Qatan et al., 2015; Qijun \& Batt, 2016; Tomasevic et al., 2013). The meeting of laws and regulations, ranked second in our survey, is similar to that of Tomasevic et al., (2013) although in their study of Chinese food businesses Bai et al., (2007) found it the least motivational factor. The least motivational factor in this survey was the potential to increase the motivation of production staff.

One of the new HACCP system implementers stated that the system protected the reputation of his firm when he faced an overseas complaint on the safety of the received products which had been 
mishandled during air transportation and he was protected from legal accountability by showing due diligence. A similar situation was also reported by Khatri \& Collins (2007).

One of the perceived HACCP benefits in the seafood business in Oman is export competitiveness and being able to break into the highly competitive markets of the EU, USA and Japan. From several faceto-face meetings with the processors, penetration to new markets or the capacity to attract new customers has not been an issue as long as FSMS are adopted. Moreover, the willingness of the Omani government in attempting to upgrade the existing control systems to ensure consumer protection has made tremendous progress with regard to HACCP implementation (Al-Busaidi et al., 2016).

\subsection{Economic impact of HACCP implementation}

Respondents in the HACCP group were requested to provide the different costs related to the preparation, implementation and operation of their HACCP system. Each processing plant will have had individual characteristics and this will greatly influence the costs involved.

A further complication was that most of the respondents were unsure of the exact costs involved (or unwilling to provide them). The respondents reported the preparation cost inclusive of overall structure and human resources to be the highest (mean of 401,000 \$US) due to structural changes in particular for the older processors and the need to employ qualified staff to operate the HACCP system.

The HACCP implementation cost (HACCP certification, audit cost and external consultancy service) were very small in comparison (mean of 3380 \$US) although it can be noted that the FQCC provided support for these services free of charge. HACCP certification is also provided by the FQCC rather than by a commercial certification body with audits carried out by Ministry officials, thereby reducing the processors' costs further. It has been reported that high operating and certification costs of HACCP system were the major problems for Mexican's meat enterprises adopting HACCP systems (Maldonado-Siman et al., 2014).

The highest reported expenditure was in the investment for new equipment and machines $(322,000$ \$US). Annual average operational costs were 63,030 \$US, with the largest component being waste management followed by training programmes, maintenance of equipment and machines and product testing (microbial, chemical, physical), with the least being record keeping. Khatri and Collins (2007) found similar outcomes with staff training, audit costs and product testing to be the largest cause of cost elevation in the processors. Time and money with lack of employee training were seen as the greatest constraints of adopting HACCP in the food business in Turkey (Murat Bas et al., 2007). Lack of understanding of HACCP system and a need of continuous training were other constraints mentioned by Tomasevic et al. (2013). Investment in new equipment, product testing and staff training were also deemed to be the main operational costs for the Mexican food industries (Maldonado et al., 2005).

Although some average figures have been given above, in general the processors faced difficulties in determining the actual cost of adopting and implementing their HACCP systems and caution is needed in interpreting the data. However, in a previous study of the seafood industries in the Sultanate of Oman, Qatan (2010) estimated the greatest cost was around 98,000 O.R per processor for structural changes although he also stressed the difficulty in obtaining reliable cost data.

It can also be commented that the FQCC organizes an annual training course by hiring a consultant to conduct professional training on FSMS targeting seafood processors and inspectors in order to overcome and reduce the cost burden of training on these processors and enhance their skills and knowledge. The processors showed eagerness to receive this type of training from the authorities as indicated by Qatan (2010) and Zaibet (2000). 


\subsection{The effectiveness of food safety legislation and control authorities}

Respondents evaluated different aspects of the regulatory control of seafood quality and safety. Most respondents were subject to the Fishery Quality Control Regulations (MD No. 12/2009) with the majority of the HACCP processors rating it as excellent in implementation. However, the nonHACCP processors had more varied views with opinions differing from 'excellent' to 'fair'. In most cases the Aquaculture and Related Quality Control Regulations (MD No. 177/2012) were not implemented as most of these processors did not process aquaculture product at the time of conducting this survey.

The implementation of the general Food Safety Law (84/2008) that was issued to protect consumer well-being was rated very good by the HACCP processors but poorly by the non-HACCP processors and, more worryingly, most of these processors were not fully aware of its existence. Nevertheless, when the officials were requested to give an opinion on the implementation of the legislation within the steps of the seafood chain (fishermen, landing sites, truckers, transportation prior to processing, processors, fish farms, distribution of processed products and markets), their response indicated that the part of the chain from 'processors' to 'distribution of processed products' was the strongest portion implementing all the legislation related to food and seafood quality and safety with the start of the chain from 'fishermen' to 'transportation' much weaker. This result agrees with the suggestion given by Qatan et al. (2015) that there is a need for a more holistic approach to promote the quality and safety of seafood throughout the entire chain from "net to plate". The quality and safety of seafood products cannot be maintained if the initial input is uncertain (Qatan et al., 2015).

The official regulation for seafood safety and the official control activities were assessed for their effectiveness and the respondents were requested to evaluate them based on a five-point Likert scale ranging from "Excellent' to 'Poor'. The responses were than split into three clusters; 'agree' for those responding with 'excellent' or 'very good', 'uncertain' for responses 'satisfactory' and 'disagree' for responses 'fair' and 'poor' as shown in Table 4. The Fishery Quality Control Regulation $(12 / 2009)$ is perceived by the Ministry as the key legal document. Respondents were asked to assess the strength of this regulation (see Table 4). All the three groups were in agreement in terms of the regulation ensuring the seafood quality and safety requirements. The officials and HACCP processors rates were in agreement with the regulation meeting the needs of different sized processing establishments although the non-HACCP processors were divided between being in agreement and disagreement. In discussion with them it was viewed as being too complicated and not easy to be implemented in their smaller operations. Asked to consider whether the regulation provides consistent application of the seafood safety requirements across different establishments in Oman, the officials and HACCP processors generally agreed but the non-HACCP processors were again split for similar reasons as before.

The effectiveness of the official control activities in enhancing seafood quality and safety was also rated by the groups and the results, split into 3 clusters (Table 4). One element of the official control operation is a sampling plan operated by the FQCC to collect samples from the processors which are submitted for physical, microbiological and chemical analysis with the emphasis on ensuring that the HACCP processors are complying with the requirements. These were seen as effective control procedures by the officials and HACCP processors but the non-HACCP processors were less consistent with their responses being between in agreement and uncertain and discussion indicated that they considered it a cost burden on small scale processors. Less than half of the officials $(46 \%)$ supported the effectiveness of the 'Recall and Revision' protocol in handling rejected products from markets. However subsequent discussion suggested some uncertainty on this point with some officials being unaware of this aspect of the legislation. Overall they felt that the current status of this system is not effective in protecting the safety and quality of seafood products and needs to be improved. In this case both groups of processors considered this protocol effective. The current level of penalties that apply to those caught breaking the rules within the Fishery Quality Control 
Regulation (12/2009), was well supported by both processors but not supported by the officials (with only $20 \%$ in agreement) who regarded them as too lenient and not sufficient to encourage compliance with the regulation. The Fisher's exact Chi-square test indicated a significant difference $(p<0.05)$ in the views of the three groups in the study for two items: the consistent application of the seafood safety requirements across different establishments and the level of violation and penalties imposed by the regulators.

When asked to indicate the frequency of official inspection, $59 \%$ of the HACCP processors indicated that they were inspected monthly which correlated well with the view of the officials (with $71 \%$ giving this response). However, only $21 \%$ of the non-HACCP processors gave this response with a larger proportion (29\%) selecting 'random inspection'. Subsequent discussion indicated that the processors situated close to Muscat (where the FQCC is based) are inspected frequently but the inspection is much less frequent for the more distant processors (for example, in Al-Wusta and AlSharqiya governorates). On the other hand, the non-HACCP processors were subject to less inspection and subsequent discussion actually indicated that they would be in favour of more inspection visits as they see them as educational and providing an opportunity to improve their staff compliance. Overall, excessive official inspection was not considered a barrier effecting the enhancement of the business operation by either the HACCP or non-HACCP processors (Figure 3 ).

As well as conducting inspections, the government can provide support to improve the safety and quality at processors. The respondents evaluated the government contribution based on a five point Likert scale ranging from 'Excellent' to 'Poor' which we have further clustered into three groups: 'agree' for those indicating 'excellent' or 'very good', 'uncertain' for 'satisfactory', and 'disagree' for 'fair' and 'poor' as shown in Table 5. Divergent responses were obtained for this question. However, all groups were in agreement with regard to 'officials response on enquires about quality and safety issues faced by the industry'. On the point relating to 'funding', it can be noted that the majority of the processors considered this to be limited although the officials tended to be more supportive of the level. Based on the views given by the study groups on the support provided by the government, the Fisher's exact Chi-square test indicated a significant difference $(p<0.05)$ for four items: funding, training, consultancy and the response by officials to HACCP enquiries.

\subsubsection{Authority's inspection reports}

A number of reports of inspections carried out by the FQCC inspectors were analysed to verify the data obtained from this survey. In general non-compliances identified in these reports were in the maintenance of facilities and equipment, cleanliness, staff hygiene, maintaining and recording time and temperature, record keeping, coding of the seafood products (traceability), recording of sensory evaluation and temperature during fish receiving and calibration of the equipment. Most of these comments were due to the improper implementation of prerequisites prior to adopting the HACCP system. The finding of the study of Bas et al. (2006) in Turkey is similar to our findings. In particular that study had highlighted inadequate time and temperature control, handwashing practices and low level of general hygiene.

Despite being repeated in subsequent reports, the inspection comments were frequently ignored by the processors delaying improvements. This could be due to a lack of communication between the officials and the processors, and insufficient training on seafood quality and safety aspects for the processors. Ensuring effective communication links between the regulatory authority and the seafood processors will enhance the efficacy and effectiveness of the inspection process (Qatan, 2010) but should be supported by enhanced professional training of both inspectors and processing staff.

Food processors are responsible and accountable for the safety of the food they produce as stated in Article 3 of the Food Safety Law (RD No.8/2008) and Article 10 of the Food Safety Regulation (MD 
No.2/2010). They are also required by Article 7 of the Fishery Quality Control Regulation to register to obtain a quality and safety control certificate (Ministerial Decision, 2009). By being registered, processors sometimes consider that this is sufficient to indicate compliance with their legal responsibilities and they rely on officials to tell them if this is not the case. Nonetheless, the processors should themselves be taking a proactive approach towards compliance.

The questionnaire asked officials to grade the effectiveness of the inspection report in covering the pre-requisite programmes (such as GMPs and GHPs) and the HACCP principles (and related CCP procedures) on a five point Likert scale from 'Excellent' to 'Poor'. The responses were also split into three clusters: 'agree' for those responding 'excellent' or 'very good', 'uncertain' for the response 'satisfactory' and 'disagree' for responses 'fair' and 'poor' as shown in Table 6-A. Although their responses were mostly supportive, it was observed that the inspection reports were mostly focusing on the different segments of the processing layout. With the exception of temperature recording, less attention was given to the identified CCPs for each processor. Again the limitations were analysed on a five point Likert scale and split into three clusters labelled 'agree' (responses 'significant' or 'major', 'uncertain' ('moderate' barrier) and 'disagree' ('limited' or 'not a barrier') as shown in Table 6-B. The officials considered lack of training, lack of laboratory support and appropriate facilities and lack of continuity and commitment of the staff from the processors as important barriers. Scattering of the responsible authorities within the ministry and lack of awareness of HACCP and its pre-requisite programs (GHPs\& GMPs) by the seafood establishments were regarded as moderate barriers limiting their ability to enforce and meet the national legislation requirements.

\section{CONCLUSION}

This study has assessed the technical barriers and benefits associated with the implementation of FSMS such as HACCP and related prerequisite programmes in the seafood processors in the Sultanate of Oman. In particular, differences between processors operating with or without a HACCP system in place have been identified. The implications of handling practices in the seafood supply chain on the safety and quality of seafood, seafood trade and the cost implications in implementing HACCP based food safety management systems were also assessed.

The responses have shown significant gaps in various aspects which undermine the effectiveness and success of implementing safety and quality requirements to meet national legislative obligations. The presence of a small-scale or artisanal sector represents a challenge in attempting to adopt modern food safety schemes and create a modern processing sector. Modernization of fishing vessels and their ability to fish at a greater range should overcome some of the current problems faced by the industry. Improved continuity of supply could reduce the impact of, or the need for, the MAF export ban that has damaged the export revenues of seafood processors.

Adoption of HACCP by the seafood processors has mostly been driven by external requirements imposed by export markets - it has not been a decision of the processors themselves to enhance their systems. Nonetheless, the requirement can be considered to be market-driven although the pressure has come from the more lucrative markets - especially that of the EU. Although the legal requirements locally require certain elements of FSMS, HACCP enforcement is not compulsory thus making the decision on implementation for many processors a commercial judgement rather than a fundamental quality and safety issue.

The majority of the surveyed seafood processors were small and medium enterprises (SMEs) which less reluctant to adopt HACCP, whereas the small-sized food enterprises have less incentive and are therefore less willing to adopt it. 
The survey has shown that HACCP implementation is made complex by a lack of well-defined prerequisites programmes and a lack of understanding of general HACCP principles. This leads to a complete dependency on HACCP to control all the hazards that arise at the different processing steps through many Critical Control Points (CCPs) increasing the financial burden of implementing the system. The requirement to restructure the facility was considered by all the participants of the study as the top barrier to the adoption of HACCP and the greatest cost. Investing in equipment was also highlighted as a major cost. However when asked to identify the negative impacts of adopting HACCP systems, the HACCP processors listed the costs of product testing as being the biggest with the cost of equipment coming second. However the top benefits perceived for HACCP were improving product quality and safety and enhanced market competitiveness allowing access to the most dynamic and highly competitive markets locally, regionally or internationally.

Further efforts are needed by the authorities to improve the entire infrastructure including fishing vessels, landing sites, markets and distribution facilities. Adopting a proactive approach throughout the entire chain from "net to plate" is fundamental to supplying seafood products which are safe and of the correct quality - this cannot be achieved without appropriate controls.

The nature of the risks associated with unsafe seafood products must be well communicated to the different stakeholders. In particular, each stakeholder should be accountable for any failure that could threaten the well-being of the end users. There is a need for sustainable training for both the authorities and employees of the processors to enhance their knowledge of HACCP and prerequisites. This would boost the confidence of inspectors allowing them to be more rigorous in enforcing national legislation. Educating consumers is also an important element as they are the end users and the driving force and, once educated and with appropriate knowledge, they can impose pressures on the food enterprises to change their attitudes and behaviour towards adopting appropriate FSMS in their businesses.

Overall the study has identified the major concerns where attention is needed. These include:

- poor attitudes and understanding toward HACCP and prerequisite programmes

- lenient enforcement

- the lack of training and consultancy organizations in the country

- a lack of awareness

- lack of food safety expertise

- the overlapping and disorganized structure of the regulatory authorities in the country

- a poor match in the inspection resources in the country and the location of the processors.

These lead to the slow development of a proper food safety culture and inadequate adoption of HACCP principles. Appropriate policies and strategies for effective food control to overcome fragmented legislation, multiple jurisdictions, and limitations in surveillance, monitoring and enforcement will enable the authorities to protect public health by enhancing seafood safety and quality and facilitate internal and external trade (FAO/WHO, 2003).

\section{Acknowledgement}

The authors will like to express their sincere gratitude to the participants from the officials of the Ministry of Agriculture and Fisheries in Oman, and the seafood processors for their valuable time and the useful responses provided for the undertaken survey. A special thank goes to Mr. Sandro Leidi, Senior Statistician at University of Reading for his valuable help with the statistical work of the study. This work was financially supported by the Ministry of Higher Education in Oman. 
Al-Busaidi, M. A., \& Jukes, D. J. (2015). Assessment of the food control systems in the Sultanate of Oman. Food Control, 51(0), 55-69. doi: http://dx.doi.org/10.1016/i.foodcont.2014.10.039

Al-Busaidi, M. A., Jukes, D. J., \& Bose, S. (2016). Seafood safety and quality: An analysis of the supply chain in the Sultanate of Oman. Food Control, 59(0), 651-662. doi: http://dx.doi.org/10.1016/i.foodcont.2015.06.023

Bai, L., Ma, C.-I., Yang, Y.-S., Zhao, S.-k., \& Gong, S.-I. (2007). Implementation of HACCP system in China: A survey of food enterprises involved. Food Control, 18(9), 11081112. doi: http://dx.doi.org/10.1016/j.foodcont.2006.07.006

Bas, M., Ersun, A. S., \& Kivanc, G. (2006). Implementation of HACCP and prerequisite programs in food businesses in Turkey. Food Control, 17(2), 118-126. doi: 10.1016/j.foodcont.2004.09.010

Bas, M., Yuksel, M., \& Cavusoglu, T. (2007). Difficulties and barriers for the implementing of HACCP and food safety systems in food businesses in Turkey. Food Control, 18(2), 124-130. doi: 10.1016/j.foodcont.2005.09.002

Doménech, E., Amorós, J. A., Pérez-Gonzalvo, M., \& Escriche, I. (2011). Implementation and effectiveness of the HACCP and pre-requisites in food establishments. Food Control, 22(8), 1419-1423. doi: http://dx.doi.org/10.1016/i.foodcont.2011.03.001

FAO/WHO. (2003). Assuring food safety and quality: Guidelines for strengthening national food control systems (FAO/WHO, Trans.). Rome, Italy: FAO: Food and Nutrition Paper 76.

Food and Veterinary Office. (2015). Overview report: Better HACCP implementation. Luxembourg: Publications Office of the European Union. http://europa.eu/index en.htm.

FSB. (2015). Fiishery Statistics Book. Fisheries Statistics and Information Department: Ministry of agriculture and Fisheries, Sultanate of Oman.

Jin, S., Zhou, J., \& Ye, J. (2008). Adoption of HACCP system in the Chinese food industry: A comparative analysis. Food Control, 19(8), 823-828. doi: 10.1016/j.foodcont.2008.01.008

Karaman, A. D., Cobanoglu, F., Tunalioglu, R., \& Ova, G. (2012). Barriers and benefits of the implementation of food safety management systems among the Turkish dairy industry: A case study. Food Control, 25(2), 732-739. doi: 10.1016/j.foodcont.2011.11.041

Khatri, Y., \& Collins, R. (2007). Impact and status of HACCP in the Australian meat industry. British Food Journal, 109(4-5), 343-354. doi: 10.1108/00070700710746768

Likert, Rensis (1932). "A Technique for the Measurement of Attitudes". Archives of Psychology. 140: 1-55.

Maldonado-Siman, E., Bai, L., Ramirez-Valverde, R., Gong, S., \& Rodriguez-de lara, R. (2014). Comparison of implementing HACCP systems of exporter Mexican and Chinese meat enterprises. Food Control, 38, 109-115. doi: 10.1016/j.foodcont.2013.10.017

Maldonado, E. S., Henson, S. J., Caswell, J. A., Leos, L. A., Martinez, P. A., Aranda, G., \& Cadena, J. A. (2005). Cost-benefit analysis of HACCP implementation in the Mexican meat industry. Food Control, 16(4), 375-381. doi: http://dx.doi.org.idpproxy.reading.ac.uk/10.1016/i.foodcont.2004.03.017

Ministerial Decision. (2009). Fishery Quality Control Regulation 12/2009. Ministry of Agriculture and Fisheries Wealth, Muscat, Sultanate of Oman. 
Mol, S., Erdogan, B. E., \& Ulusoy, S. (2014). Survey into the Characteristics, Working Conditions and Deficiencies of Turkish Seafood Processing Firms. Turkish Journal of Fisheries and Aquatic Sciences, 14(3), 705-712. doi: 10.4194/1303-2712-v14_3_13

Qatan, S. (2010). Evaluating the Governance System of Seafood Quality and Safety: A Surveybased Case Study of Seafood Industries in the Sultanate of Oman. (Master of Science), Sultan Qaboos University, Sultanate of Oman.

Qatan, S., Bose, S., \& Mothershaw, A. (2015). Stakeholders' views on the status of the fish quality and safety regulatory schemes The case of the sultanate of Oman. British Food Journal, 117(4), 1303-1314. doi: 10.1108/bfj-12-2013-0359

Qijun, J., \& Batt, P. J. (2016). Barriers and benefits to the adoption of a third party certified food safety management system in the food processing sector in Shanghai, China. Food Control, 62, 89-96. doi: http://dx.doi.org/10.1016/i.foodcont.2015.10.020

Ropkins, K., \& Beck, A. J. (2000). Evaluation of worldwide approaches to the use of HACCP to control food safety. Trends in Food Science and Technology, 11(1), 10-21. doi: 10.1016/S0924-2244(00)00036-4

Tomasevic, I., Smigic, N., Djekic, I., Zaric, V., Tomic, N., \& Rajkovic, A. (2013). Serbian meat industry: A survey on food safety management systems implementation. Food Control, 32(1), 25-30. doi: 10.1016/j.foodcont.2012.11.046

Zaibet, L. (2000). Compliance to HACCP and Competitiveness of Oman Fish Processing. International Food and Agribusiness Management Review, 3, 311-321. 


\section{List of tables and figures}

\section{List of tables:}

- Table 1: Respondent's Profile

- Table 2: Characteristics of the seafood processors

- Table 3: The main barriers to export to regional and international markets

- Table 4: The effectiveness of the official regulation and control activities

- Table 5: Assessing the government contribution to address seafood quality and safety issues in the seafood processors

- Table 6: The effectiveness of the inspection report and the limitation faced by the inspectors to meet national legislative requirements (Officials, $n=15$ )

\section{List of Figures:}

- Figure 1: Destination markets of the end seafood products

- Figure 2: Mean values of the level of difficulty accessing international markets in terms of quality and safety requirement based on a five scale ranging from "very difficult" (5) to "very easy" (1)

- Figure 3: Overall mean values of the barriers that are likely to prevent the enhancement of the business operation in the seafood sector (combined data)

- Figure 4: Overall mean values of the degree of negative impact on the seafood quality and safety at the different stages of the seafood supply chain based on a Likert scale ranging from "Major Impact" (5) "to the No impact" (1)

- Figure 5: Overall mean values of the factors in the supply chain that have negative impact on seafood quality and safety based on a Likert scale ranging from "Major Impact" (5) "to the No impact" (1)

- $\quad$ Figure 6. Mean values of the levels of implementation of the following of the prerequisites programmes in the seafood processors based on a five scale ranging from "Full" (5) to "None" (1)

- $\quad$ Figure 7: The respondents' \% of the officials and the seafood processors of the main barriers to adopt HACCP prior to implementing the system based on a rank from 'first' (1st) to 'fifth' (5th)

- $\quad$ Figure 8: The HACCP processors respondents of the negative impacts after HACCP implementation in the seafood processors based on a rank from 'first' (1st) to 'fifth' (5th)

- $\quad$ Figure 9: The respondents' \% of the top motivational factors after implementing HACCP on the seafood businesses based on a rank from 'first' (1st) to 'fifth' (5th)

- Figure 10: The HACCP processors respondents of the benefits of implementing HACCP in the seafood processors based on a rank from 'first' (1st) to 'fifth' (5th) 


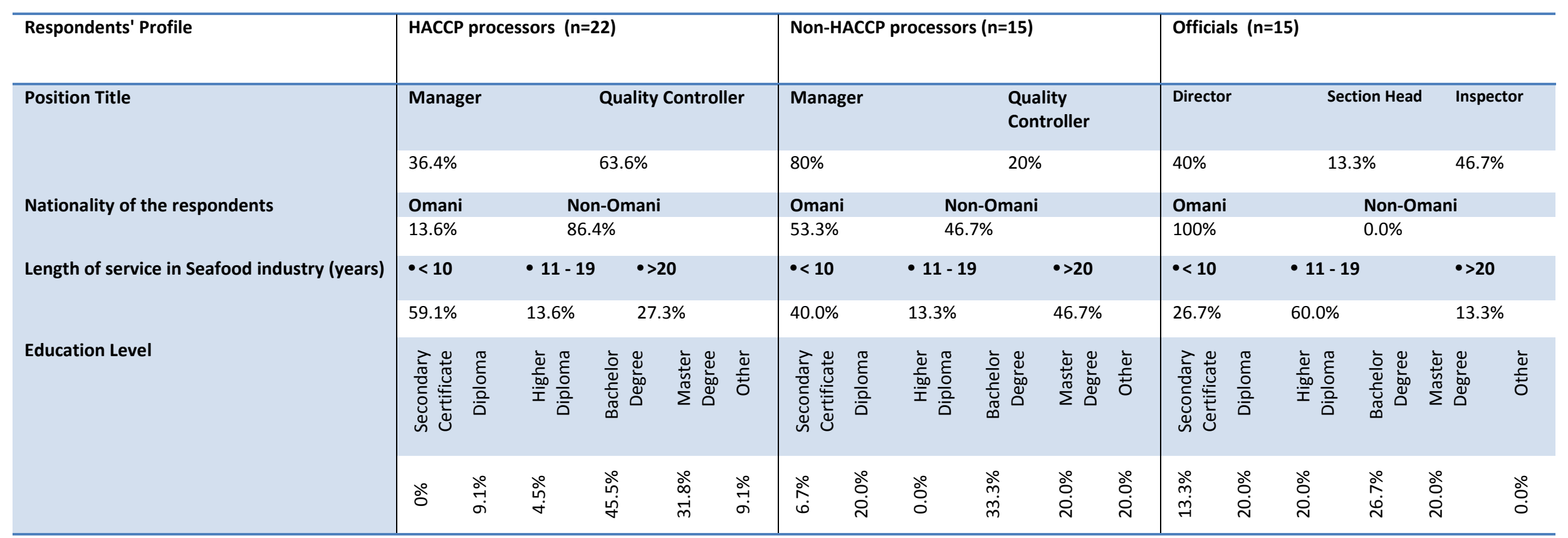




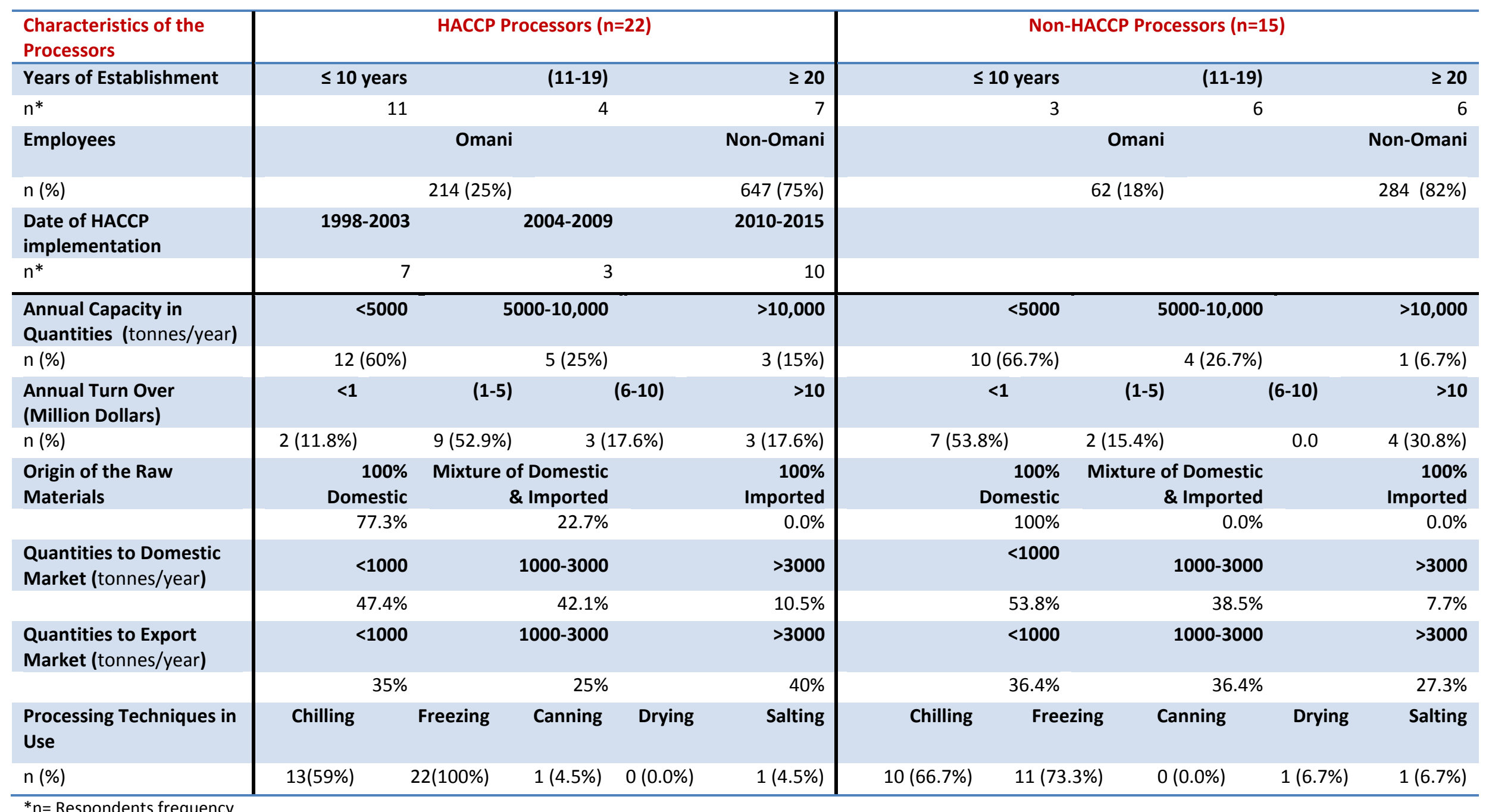

${ }^{*} n=$ Respondents frequency 


\begin{tabular}{|c|c|c|c|c|c|c|c|c|c|}
\hline $\begin{array}{l}\text { Barriers to } \\
\text { Export } \\
\text { Frequency } \\
\text { (\%) }\end{array}$ & $\begin{array}{c}\text { Trade } \\
\text { restrictions } \\
\text { (SPS) \& } \\
\text { (TBT) }\end{array}$ & $\begin{array}{c}\text { Lack of } \\
\text { consumer } \\
\text { demand } \\
\text { in specific } \\
\text { market }\end{array}$ & $\begin{array}{c}\text { Uncertainty } \\
\text { in obtaining } \\
\text { a regular } \\
\text { supply of } \\
\text { raw } \\
\text { materials }\end{array}$ & $\begin{array}{l}\text { Exchange } \\
\text { rate } \\
\text { fluctuations }\end{array}$ & $\begin{array}{l}\text { Administrative } \\
\text { delay locally }\end{array}$ & $\begin{array}{c}\text { Administrative } \\
\text { delay in the } \\
\text { destination } \\
\text { country }\end{array}$ & $\begin{array}{c}\text { Export } \\
\text { bans of } \\
\text { certain fish } \\
\text { species by } \\
\text { the MAF }\end{array}$ & $\begin{array}{c}\text { Import } \\
\text { duty (tax) } \\
\text { in foreign } \\
\text { market }\end{array}$ & Others \\
\hline Officials & $4(10.3 \%)$ & $6(15.4 \%)$ & $8(20.5 \%)$ & $2(5.1 \%)$ & $6(15.4 \%)$ & $3(7.7 \%)$ & $8(20.5 \%)$ & $1(2.6 \%)$ & $1(2.6 \%)$ \\
\hline $\begin{array}{l}\text { HACCP } \\
\text { Processors }\end{array}$ & $5(8.2 \%)$ & $4(6.6 \%)$ & $15(24.6 \%)$ & $5(8.2 \%)$ & $3(4.9 \%)$ & $1(1.6 \%)$ & $18(29.5 \%)$ & $8(13.1 \%)$ & $2(3.3 \%)$ \\
\hline $\begin{array}{l}\text { Non HACCP } \\
\text { Processors }\end{array}$ & $4(8.7 \%)$ & $3(6.5 \%)$ & $7(15.2 \%)$ & $4(8.7 \%)$ & $11(23.9 \%)$ & $1(2.2 \%)$ & $12(26.1 \%)$ & $1(2.2 \%)$ & $3(6.5 \%)$ \\
\hline
\end{tabular}




\begin{tabular}{|c|c|c|c|c|c|}
\hline & $\begin{array}{l}\text { TARGETED } \\
\text { GROUPS* }\end{array}$ & $\begin{array}{c}\text { AGREE } \\
\text { Frequency (\%) }\end{array}$ & $\begin{array}{l}\text { UNCERTAIN } \\
\text { Frequency (\%) }\end{array}$ & $\begin{array}{c}\text { DIS-AGREE } \\
\text { Frequency (\%) }\end{array}$ & $\begin{array}{c}X_{2} \text { test } \\
p \text {-value** }\end{array}$ \\
\hline \multicolumn{6}{|l|}{$\begin{array}{l}\text { The assessment of the } \\
\text { strength of the Fishery } \\
\text { Quality Control Regulation } \\
\text { (12/2009) requirements in } \\
\text { achieving the following: }\end{array}$} \\
\hline \multirow{3}{*}{$\begin{array}{l}\text { Ensuring seafood quality and } \\
\text { safety }\end{array}$} & $A$ & $13(86.7 \%)$ & $1(6.7 \%)$ & $1(6.7 \%)$ & 0.425 \\
\hline & $\mathrm{B}$ & 19 (86.4\%) & $3(13.6 \%)$ & $0(00.0 \%)$ & \\
\hline & $\mathrm{C}$ & $10(71.4 \%)$ & $2(14.3 \%)$ & $2(14.3 \%)$ & \\
\hline \multirow{3}{*}{$\begin{array}{l}\text { Meeting the needs of } \\
\text { different sized processing } \\
\text { establishments }\end{array}$} & A & $11(73.3 \%)$ & $3(20.0 \%)$ & $1(6.7 \%)$ & 0.171 \\
\hline & B & $14(63.6 \%)$ & $6(27.3 \%)$ & $2(9.1 \%)$ & \\
\hline & $\mathrm{C}$ & $5(35.7 \%)$ & $4(28.6 \%)$ & $5(35.7 \%)$ & \\
\hline \multirow{3}{*}{$\begin{array}{l}\text { Providing consistent } \\
\text { application of the seafood } \\
\text { safety requirements across } \\
\text { different establishments in } \\
\text { Oman }\end{array}$} & $A$ & $9(60.0 \%)$ & $6(40 \%)$ & $0(00.0 \%)$ & 0.030 \\
\hline & $\mathrm{B}$ & 15 (68.2\%) & $4(18.2 \%)$ & $3(13.6 \%)$ & \\
\hline & C & $6(42.9 \%)$ & $2(14.3 \%)$ & $6(42.9 \%)$ & \\
\hline \multicolumn{6}{|l|}{$\begin{array}{l}\text { The effectiveness of the } \\
\text { official control activities in } \\
\text { enhancing seafood quality } \\
\text { and safety: }\end{array}$} \\
\hline \multirow[t]{3}{*}{ Inspection process } & $A$ & $10(66.7 \%)$ & $4(26.7 \%)$ & $1(6.7 \%)$ & 0.807 \\
\hline & B & $16(72.7 \%)$ & $5(22.7 \%)$ & $1(4.5 \%)$ & \\
\hline & $\mathrm{C}$ & $8(53.3 \%)$ & $5(33.3 \%)$ & $2(13.3 \%)$ & \\
\hline \multirow[t]{2}{*}{ Auditing process (QC Holder) } & $A$ & $12(80.0 \%)$ & $2(13.3 \%)$ & $1(6.7 \%)$ & 1.000 \\
\hline & B & $17(77.3 \%)$ & $3(13.6 \%)$ & $2(9.1 \%)$ & \\
\hline \multirow[t]{3}{*}{ Sampling plan } & $A$ & $9(60.0 \%)$ & $5(33.3 \%)$ & $1(6.7 \%)$ & 0.883 \\
\hline & B & 13 (59.1\%) & $8(36.4 \%)$ & $1(4.5 \%)$ & \\
\hline & $\mathrm{C}$ & $7(46.7 \%)$ & $6(40.0 \%)$ & $2(13.3 \%)$ & \\
\hline \multirow[t]{3}{*}{ Sample analysis } & $A$ & $9(60.0 \%)$ & $6(40.0 \%)$ & $0(0.0 \%)$ & 0.815 \\
\hline & B & $12(54.5 \%)$ & $8(36.4 \%)$ & $2(9.1 \%)$ & \\
\hline & $\mathrm{C}$ & $7(46.7 \%)$ & $6(40.0 \%)$ & $2(13.3 \%)$ & \\
\hline \multirow{3}{*}{$\begin{array}{l}\text { Pre-requisite programs such } \\
\text { as GHPs\& GMPs }\end{array}$} & $A$ & $12(80.0 \%)$ & $2(13.3 \%)$ & $1(6.7 \%)$ & 0.936 \\
\hline & B & 15 (68.2\%) & $5(22.7 \%)$ & $2(9.1 \%)$ & \\
\hline & $\mathrm{C}$ & $10(66.7 \%)$ & $3(20.0 \%)$ & $2(13.3 \%)$ & \\
\hline \multirow[t]{3}{*}{ HACCP/ISO22000 } & $A$ & $10(66.7 \%)$ & $5(33.3 \%)$ & $0(0.0 \%)$ & 0.105 \\
\hline & B & 19 (86.4\%) & $2(9.1 \%)$ & $1(4.5 \%)$ & \\
\hline & $\mathrm{C}$ & $9(60.0 \%)$ & $3(20.0 \%)$ & $3(20.0 \%)$ & \\
\hline \multirow{3}{*}{$\begin{array}{l}\text { 'Recall and Revision' protocol } \\
\text { in handling rejected products } \\
\text { from markets }\end{array}$} & $A$ & $7(46.7 \%)$ & $4(26.7 \%)$ & $4(26.7 \%)$ & 0.449 \\
\hline & B & 13 (59.1\%) & $8(36.4 \%)$ & $1(4.5 \%)$ & \\
\hline & $\mathrm{C}$ & $9(60.0 \%)$ & $4(26.7 \%)$ & $2(13.3 \%)$ & \\
\hline \multirow{3}{*}{$\begin{array}{l}\text { Level of violation and } \\
\text { penalties that apply to those } \\
\text { caught breaking the rules } \\
\text { within the Fishery Quality } \\
\text { Control Regulation (12/2009) }\end{array}$} & $A$ & $3(20.0 \%)$ & 7 (46.7\%) & $5(33.3 \%)$ & 0.013 \\
\hline & B & $16(72.7 \%)$ & $4(18.2 \%)$ & $2(9.1 \%)$ & \\
\hline & C & $8(53.3 \%)$ & $2(13.3 \%)$ & $5(33.3 \%)$ & \\
\hline
\end{tabular}




\begin{tabular}{|c|c|c|c|c|c|}
\hline $\begin{array}{l}\text { QUESTIONNAIRE } \\
\text { STATEMENTS }\end{array}$ & $\begin{array}{l}\text { TARGETED } \\
\text { GROUPS* }\end{array}$ & $\begin{array}{c}\text { AGREE } \\
\text { Frequency (\%) }\end{array}$ & $\begin{array}{l}\text { UNCERTAIN } \\
\text { Frequency (\%) }\end{array}$ & $\begin{array}{l}\text { DIS-AGREE } \\
\text { Frequency (\%) }\end{array}$ & $\begin{array}{c}X_{2} \text { test } \\
p \text {-value** }\end{array}$ \\
\hline \multirow[t]{3}{*}{ Funding } & $A$ & $6(40.0 \%)$ & $5(33.3 \%)$ & $4(26.7 \%)$ & 0.022 \\
\hline & B & $3(13.6 \%)$ & $3(13.6 \%)$ & $16(72.7 \%)$ & \\
\hline & $\mathrm{C}$ & $1(6.7 \%)$ & $2(13.3 \%)$ & 12 (80.0\%) & \\
\hline \multirow[t]{3}{*}{ Training } & $A$ & $5(33.3 \%)$ & $5(33.3 \%)$ & $5(33.3 \%)$ & 0.027 \\
\hline & B & $10(45.5 \%)$ & $5(22.7 \%)$ & 7 (31.8\%) & \\
\hline & $\mathrm{C}$ & $1(6.7 \%)$ & $2(13.3 \%)$ & 12 (80.0 \%) & \\
\hline \multirow[t]{3}{*}{ Consultancy } & $A$ & $10(66.7 \%)$ & $3(20.0 \%)$ & $2(13.3 \%)$ & 0.019 \\
\hline & B & $13(59.1 \%)$ & $5(22.7 \%)$ & $4(18.2 \%)$ & \\
\hline & $\mathrm{C}$ & $2(13.3 \%)$ & $5(33.3 \%)$ & $8(53.3 \%)$ & \\
\hline \multirow[t]{3}{*}{ Technical advice } & $A$ & $11(73.3 \%)$ & $2(13.3 \%)$ & $2(13.3 \%)$ & 0.068 \\
\hline & B & $14(63.4 \%)$ & $5(22.7 \%)$ & $3(13.6 \%)$ & \\
\hline & $\mathrm{C}$ & $4(26.7 \%)$ & $4(26.7 \%)$ & 7 (46.7\%) & \\
\hline \multirow{3}{*}{$\begin{array}{l}\text { Communication with } \\
\text { establishment }\end{array}$} & A & $10(66.7 \%)$ & $4(26.7 \%)$ & $1(6.7 \%)$ & 0.160 \\
\hline & B & $15(68.2 \%)$ & $3(13.6 \%)$ & $4(18.2 \%)$ & \\
\hline & $\mathrm{C}$ & $5(33.3 \%)$ & $5(33.3 \%)$ & $5(33.3 \%)$ & \\
\hline \multirow{3}{*}{$\begin{array}{l}\text { Response of officials to } \\
\text { enquires about quality and } \\
\text { safety issues faced by the } \\
\text { industry }\end{array}$} & $A$ & $11(73.3 \%)$ & $3(20.0 \%)$ & $1(6.7 \%)$ & 0.667 \\
\hline & B & $13(59.1 \%)$ & $5(22.7 \%)$ & $4(18.2 \%)$ & \\
\hline & $\mathrm{C}$ & $7(46.7 \%)$ & $5(33.3 \%)$ & $3(20.0 \%)$ & \\
\hline \multirow{3}{*}{$\begin{array}{l}\text { Response of the officials to } \\
\text { enquires about the HACCP } \\
\text { system }\end{array}$} & $A$ & $13(86.7 \%)$ & $1(6.7 \%)$ & $1(6.7 \%)$ & 0.008 \\
\hline & B & $17(77.3 \%)$ & $3(13.6 \%)$ & $2(9.1 \%)$ & \\
\hline & $\mathrm{C}$ & $6(40.0 \%)$ & $1(6.7 \%)$ & $8(53.3 \%)$ & \\
\hline
\end{tabular}

$* A=$ Officials $(n=15) ; B=$ HACCP-Processors $(n=22) ; C=$ Non-HACCP Processors $(n=15)$

** $p<0.05$ 
A. The effectiveness of the inspection

Agree

Uncertain

Dis-Agree report in covering the following:

Frequency (\%) Frequency (\%) Frequency (\%)

- Good Manufacturing Practices (GMPs) $10(66.7 \%)$ $4(26.7 \%)$ $1(6.7 \%)$

- Good Hygiene Practices (GHPs) $9(60.0 \%)$

$6(40.0 \%)$ $0(0.0 \%)$

- HACCP $9(60.0 \%)$ $4(26.7 \%)$

$2(13.3 \%)$

B. The factors limiting the ability of the inspectors to enforce the regulations related to seafood quality and safety

\section{Not/Limited \\ Barrier \\ Frequency (\%)} control during performing the inspections duties

\begin{tabular}{|c|c|c|c|c|}
\hline$\bullet$ & Lack of time & $10(66.7 \%)$ & $2(13.3 \%)$ & $3(20.0 \%)$ \\
\hline$\bullet$ & Lack of training & $6(40.0 \%)$ & $2(13.3 \%)$ & $7(46.7 \%)$ \\
\hline$\bullet$ & Lack of laboratory support/facilities & $4(26.7 \%)$ & $5(33.3 \%)$ & $6(40.0 \%)$ \\
\hline$\bullet$ & Lack of transport & $9(60.0 \%)$ & $5(33.3 \%)$ & $1(6.7 \%)$ \\
\hline & $\begin{array}{l}\text { Scattering of the responsible } \\
\text { authorities within the ministry }\end{array}$ & $6(40.0 \%)$ & $7(46.7 \%)$ & $2(13.3 \%)$ \\
\hline & $\begin{array}{l}\text { Low priority within the government to } \\
\text { effectively enforcing legislation }\end{array}$ & $8(53.3 \%)$ & $5(33.3 \%)$ & $2(13.3 \%)$ \\
\hline & $\begin{array}{l}\text { Lack of continuity and commitments of } \\
\text { the staff from the establishments }\end{array}$ & $3(20.0 \%)$ & $4(26.7 \%)$ & $8(53.3 \%)$ \\
\hline & $\begin{array}{l}\text { Lack of continuity of the staff from the } \\
\text { ministry }\end{array}$ & $10(66.7 \%)$ & $4(26.7 \%)$ & $1(6.7 \%)$ \\
\hline & $\begin{array}{l}\text { Lack of awareness of HACCP and its pre- } \\
\text { requisite programs (GHPs\& GMPs) by } \\
\text { the seafood establishments }\end{array}$ & $4(26.7 \%)$ & $8(53.3 \%)$ & $3(20.0 \%)$ \\
\hline
\end{tabular}

Moderate Significant/Major

Barrier Barrier

Frequency (\%) Frequency (\%) 


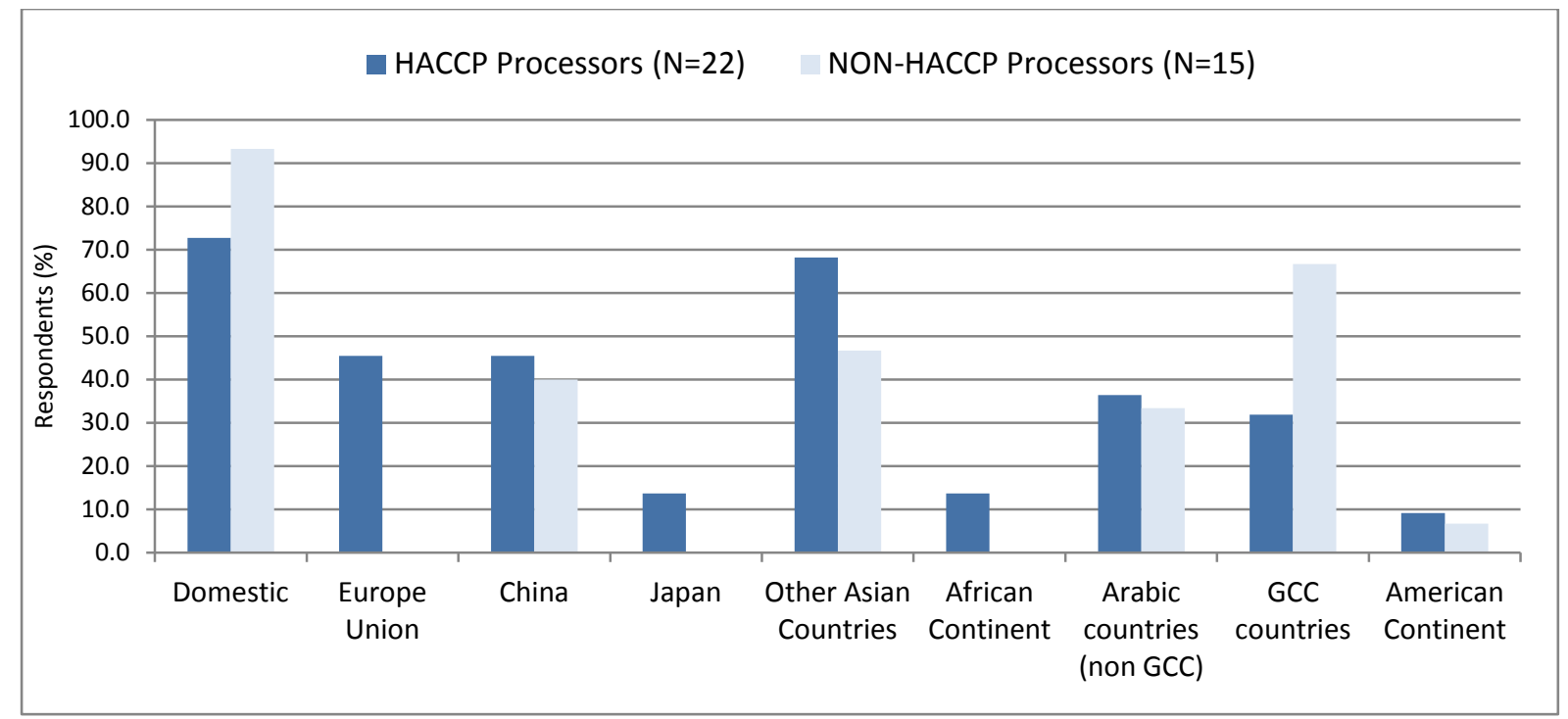




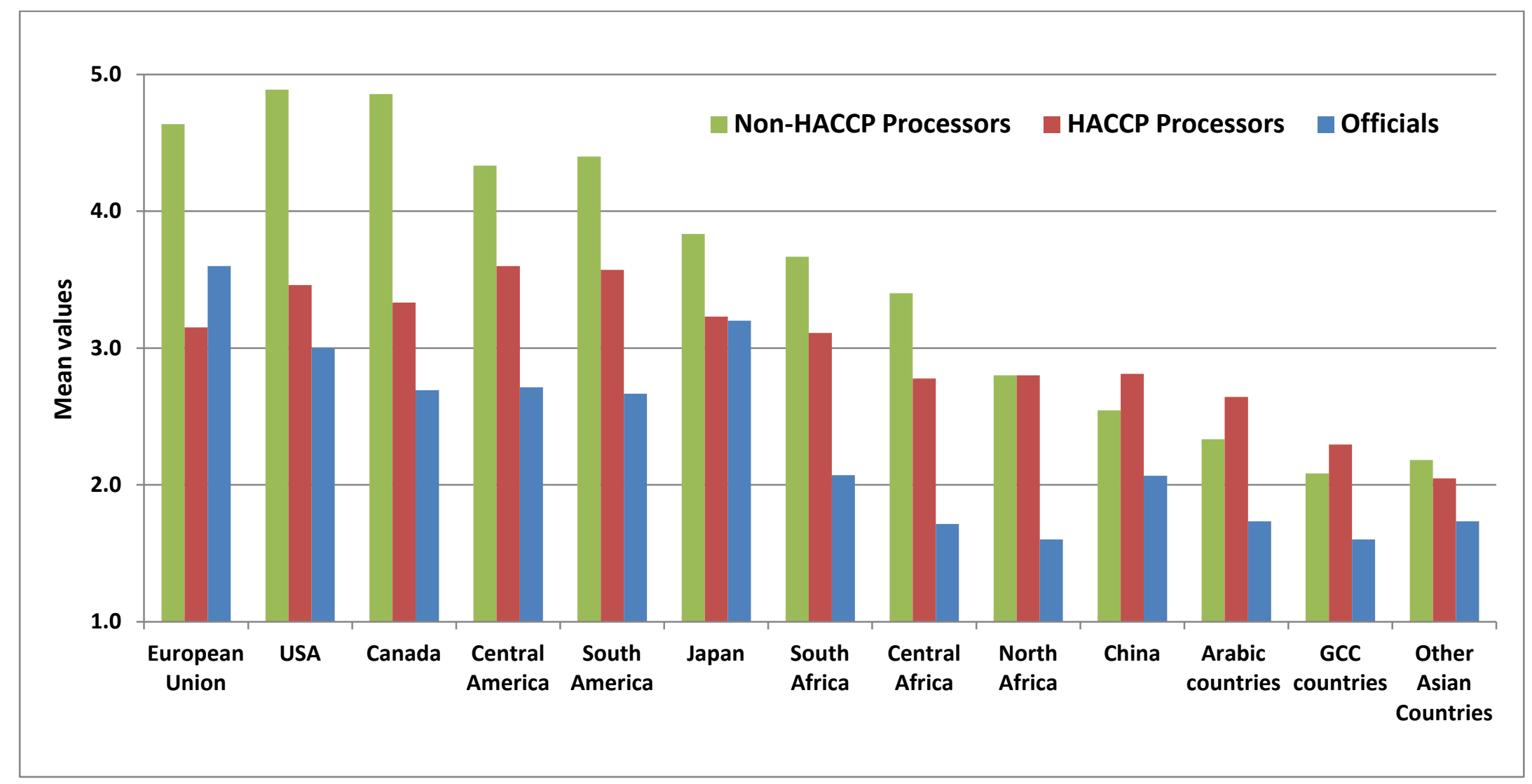


Export ban of certain fish species by the authority Sudden changes in government policies Lack of raw seafood materials Cost of the raw seafood materials

Difficulty in getting experienced employees Lack of financial capital Lack of authorities' support Staff turnover

Lack of enforcement of laws and regulations

Lack of investment in new technology Lack of communication with the authorities Lack of access to information on different markets Lack of management dedication Excessive official inspection Low levels of official inspection

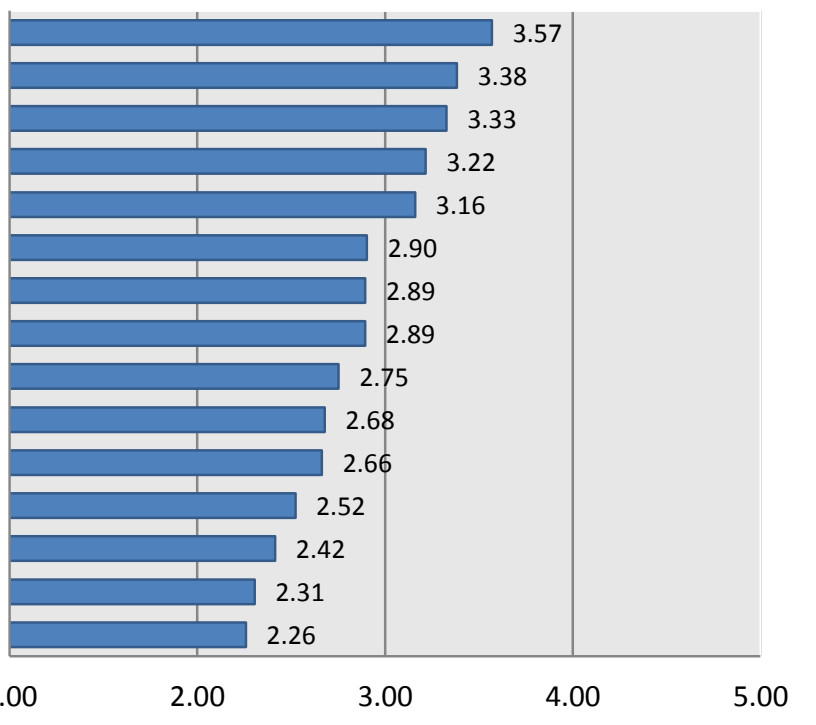




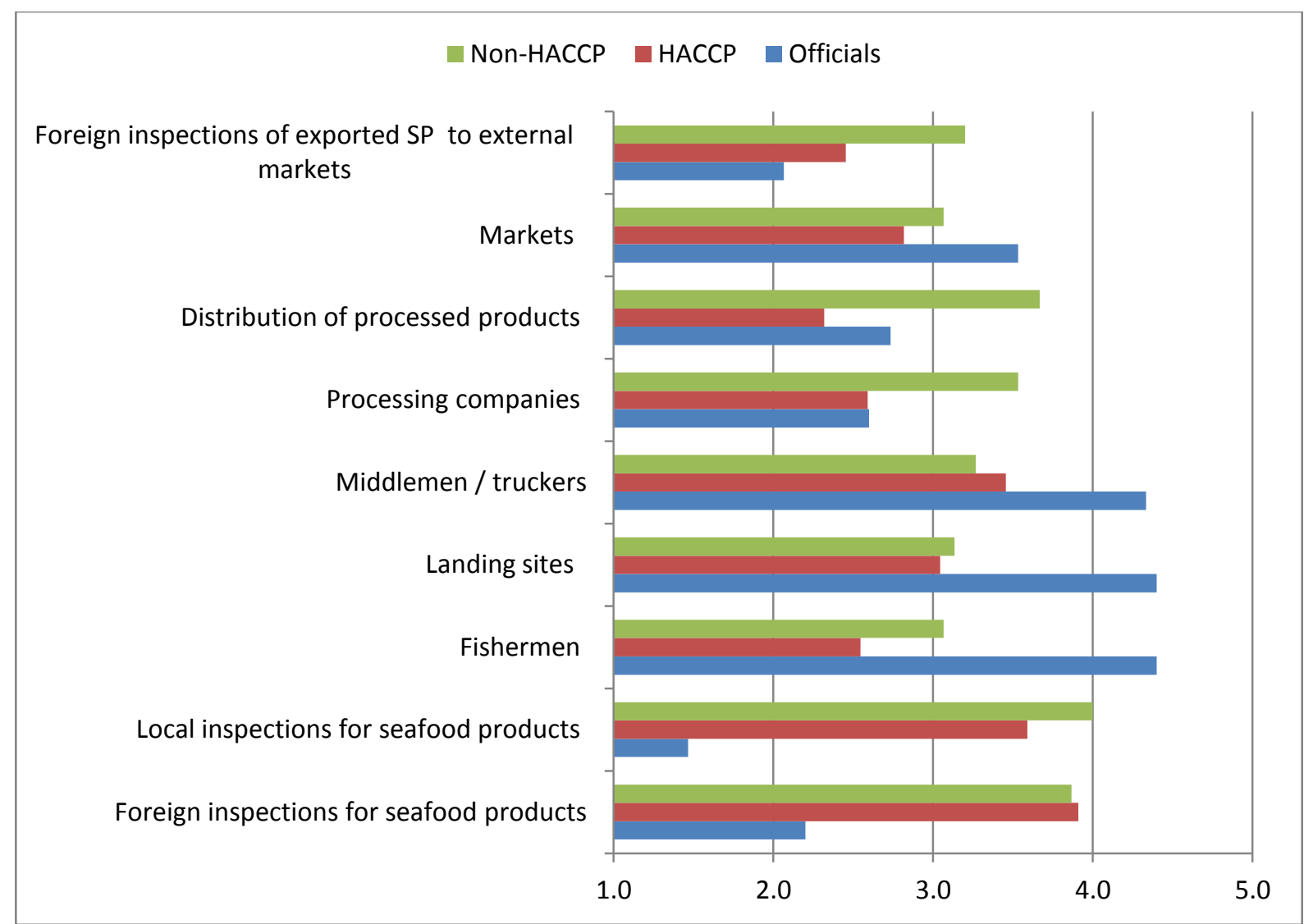




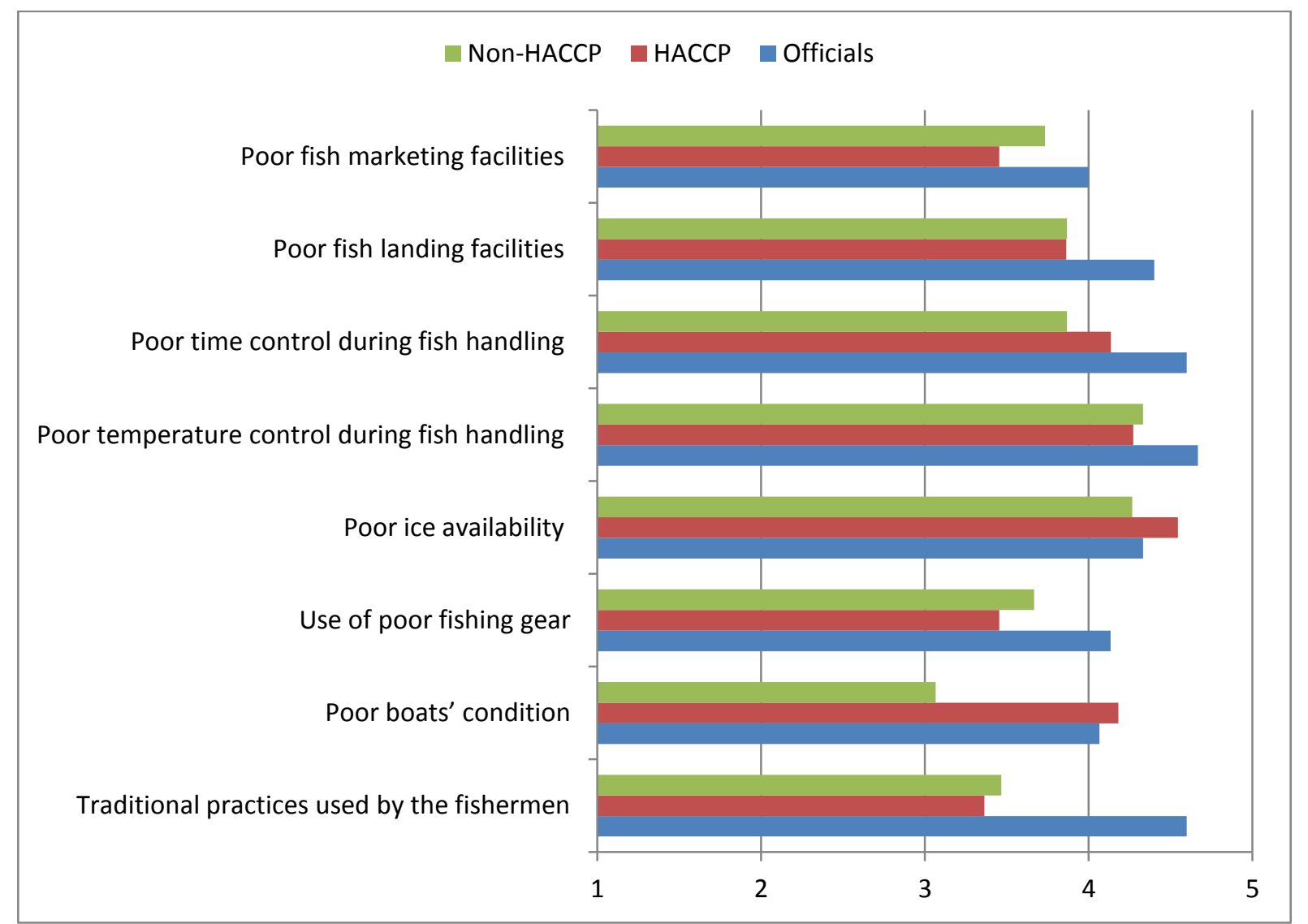



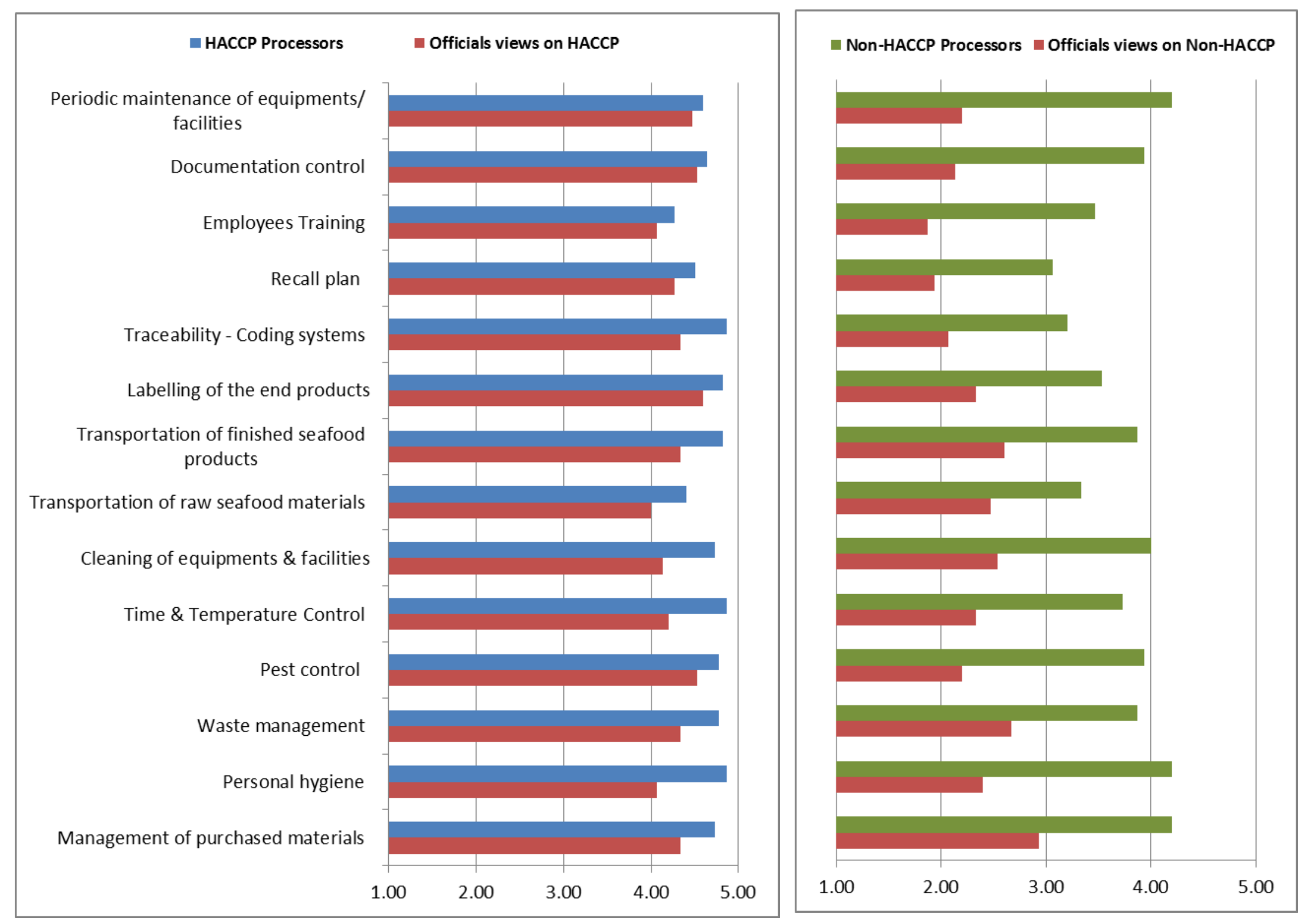

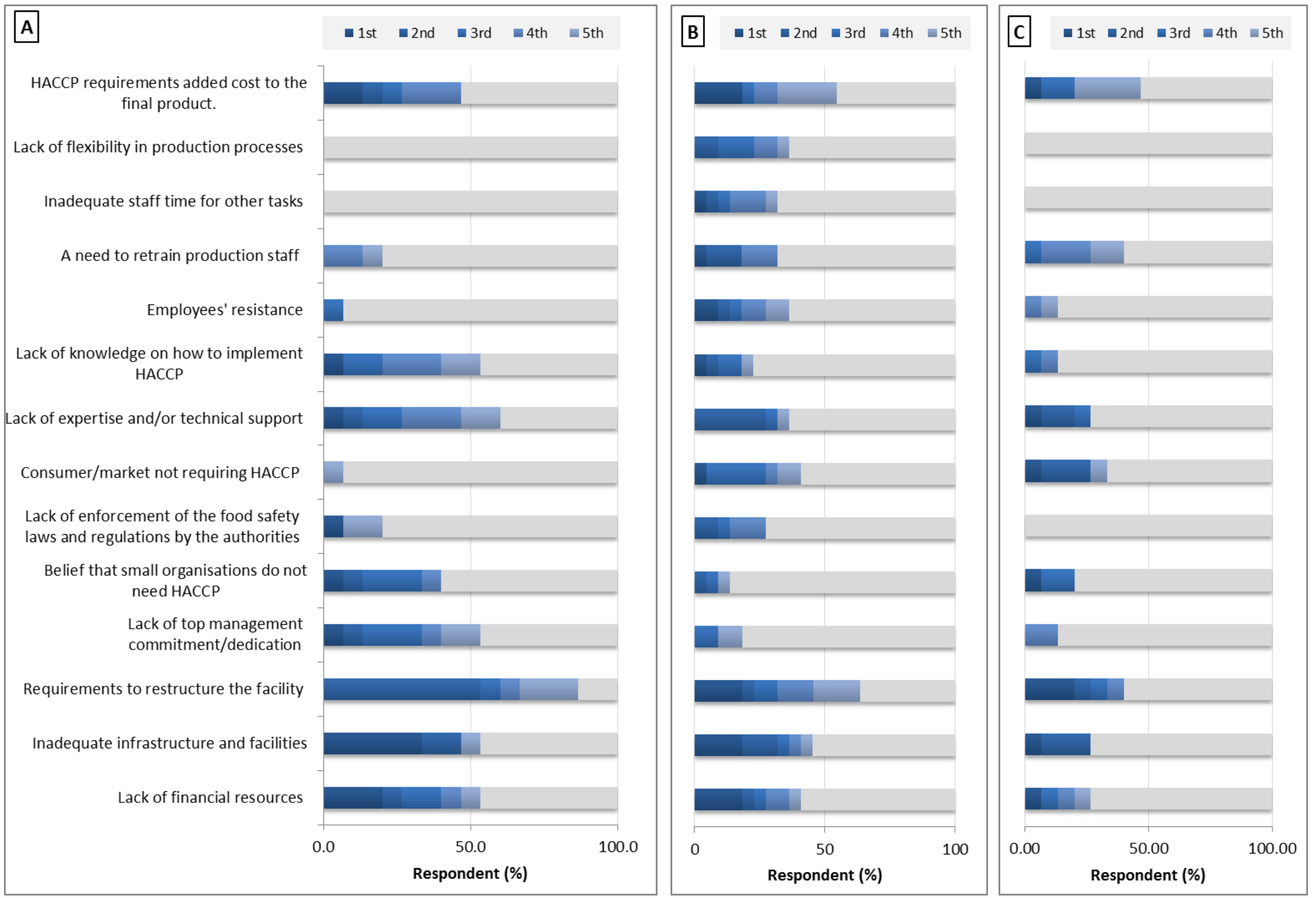
* $A=$ Officials; $B=$ HACCP-Processors; $C=$ Non-HACCP Processors 


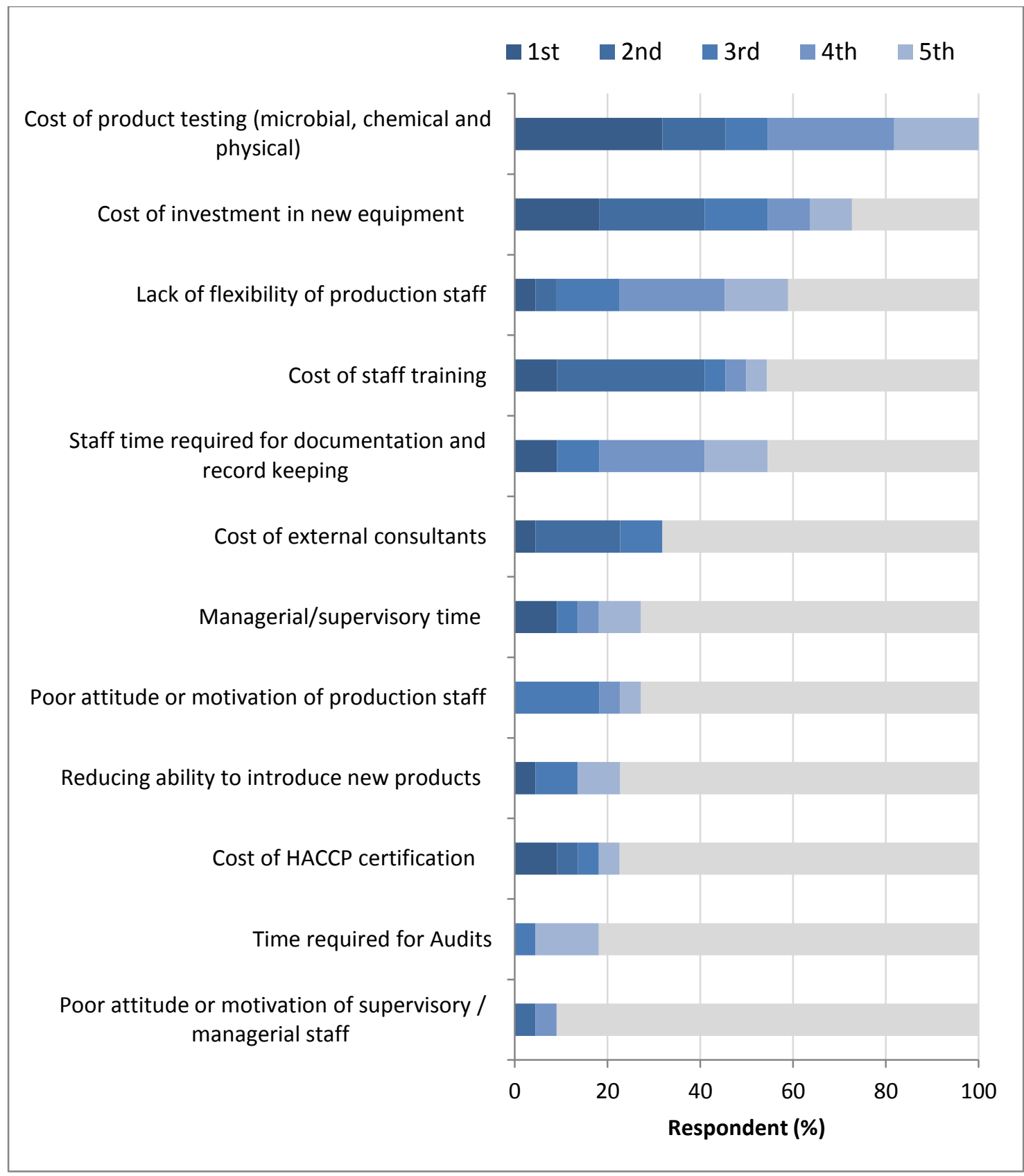



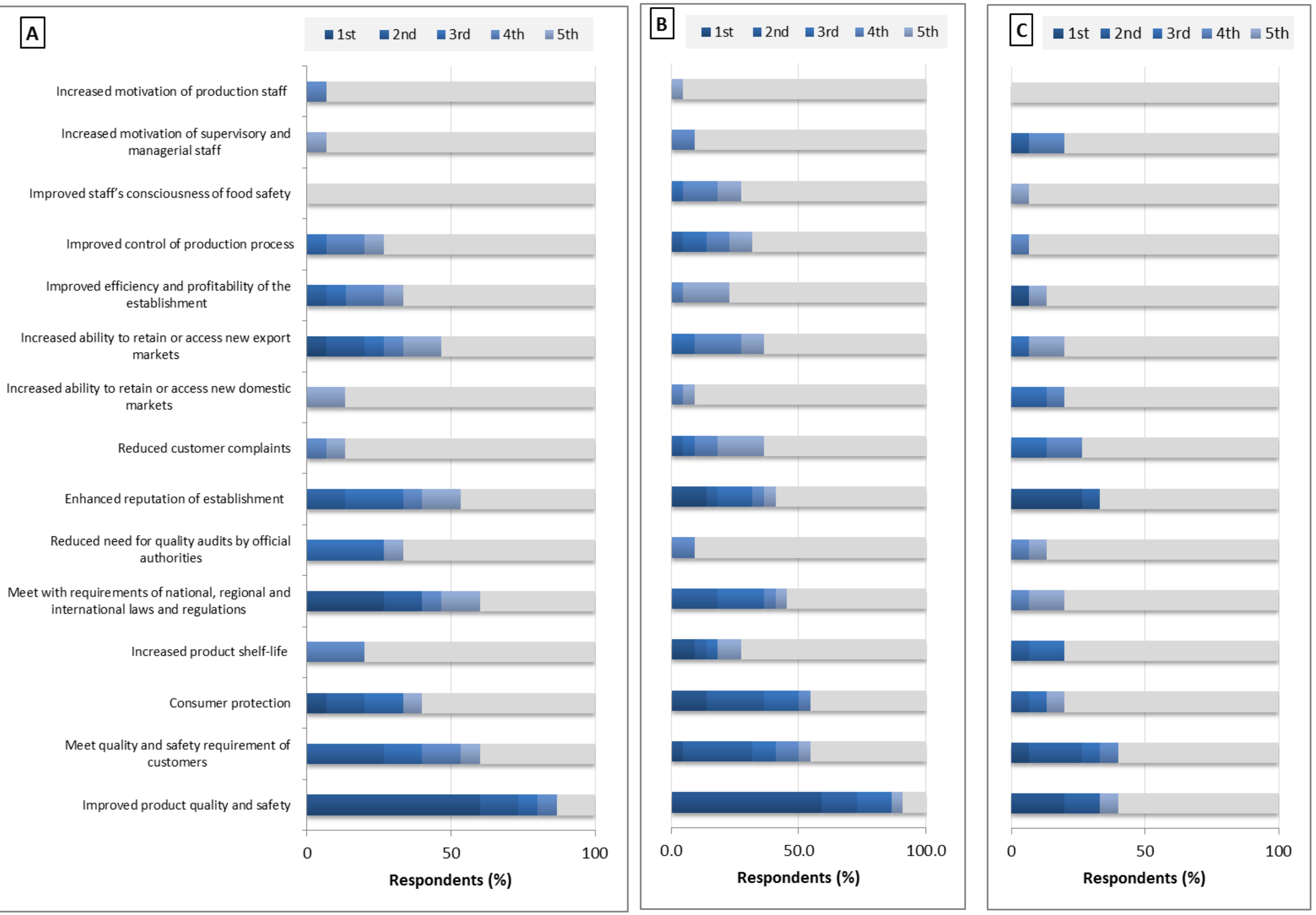
* A= Officials; $B=$ HACCP-Processors; $C=$ Non-HACCP Processors 


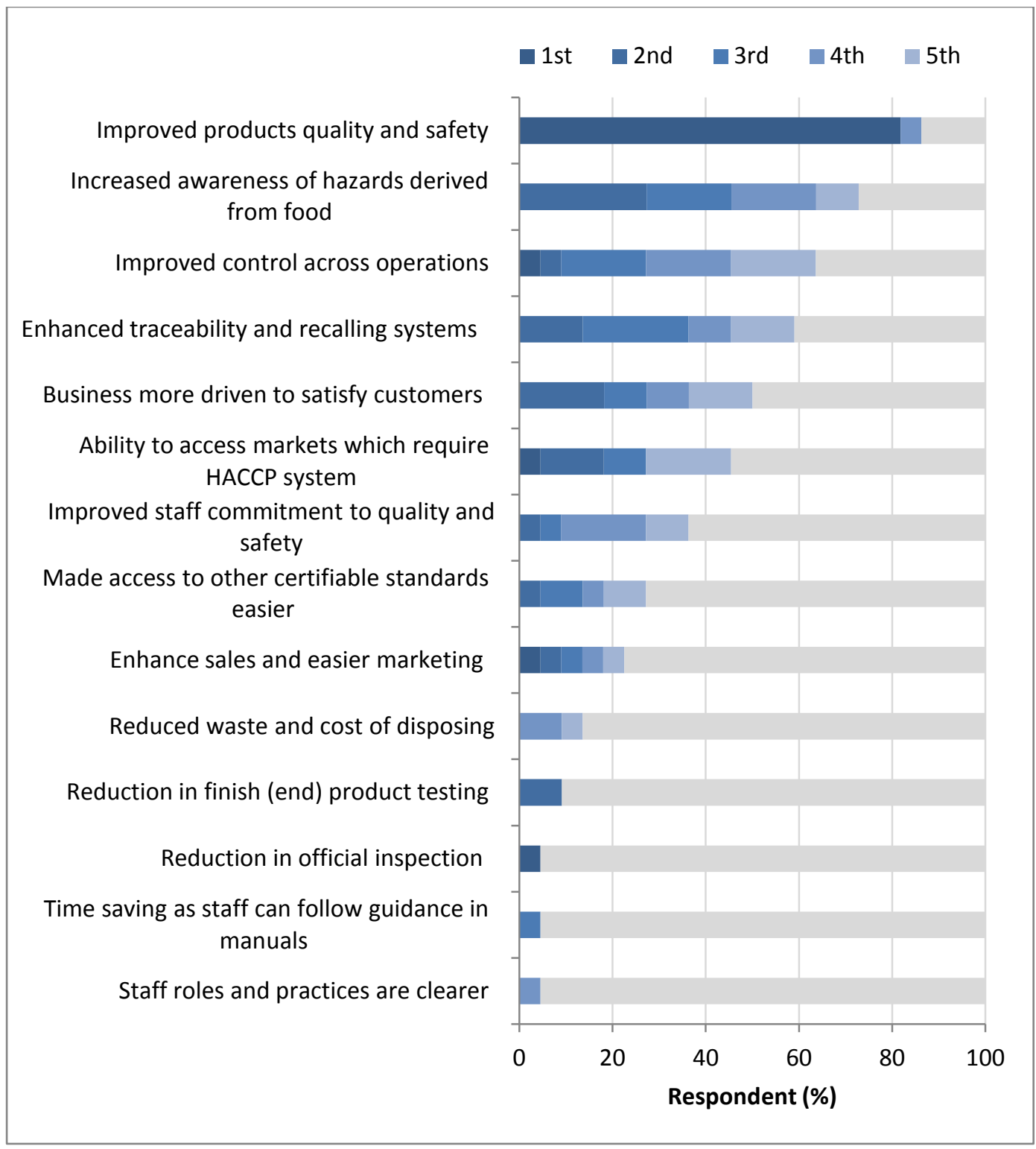




\section{Highlights:}

- The research assessed HACCP implementation in the Omani seafood sector

- Significant gaps in aspects of seafood safety and quality are highlighted

- The use of HACCP in Omani seafood processors is limited and the reasons assessed

- The poor use of prerequisites programmes makes HACCP implementation more complex

- Inspection resources and the location of the processors are poorly matched 